\title{
Multiple Lesions Contribute to Infertility in Males Lacking Autoimmune Regulator
}

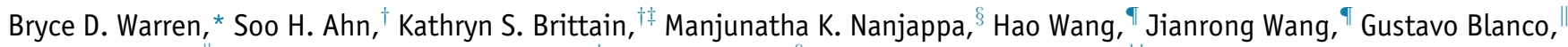
Gladis Sanchez, ${ }^{*}$ Yong Fan, ${ }^{* *}$ Brian K. Petroff, ${ }^{\dagger}$ Paul S. Cooke, ${ }^{\S}$ and Margaret G. Petroff ${ }^{* \dagger}$

From the Departments of Anatomy and Cell Biology* and Molecular and Integrative Physiology," University of Kansas Medical Center, Kansas City, Kansas; the Department of Pathobiology and Diagnostic Investigation, ${ }^{\dagger}$ College of Veterinary Medicine, the Cell and Molecular Biology Graduate Program, ${ }^{\ddagger}$ College of Natural Sciences, and the Department of Computational Mathematics, Science and Engineering, " College of Engineering, Michigan State University, East Lansing, Michigan; the Department of Physiological Sciences, ${ }^{\S}$ College of Veterinary Medicine, University of Florida, Gainesville, Florida; and the Institute of Cellular Therapeutics, ** Alleghany Health Network, Pittsburgh, Pennsylvania

\author{
Accepted for publication \\ May 18, 2021. \\ Address correspondence to \\ Margaret G. Petroff, Ph.D., \\ Department of Pathology and \\ Diagnostic Investigation, Michi- \\ gan State University, 474 S. \\ Shaw Ln., East Lansing, MI, \\ 48824. E-mail: petrof10@msu. \\ edu.
}

Infertility affects up to $25 \%$ of reproductive-age couples worldwide. ${ }^{1,2}$ Historically, compromised fertility has most often been attributed to female pathologies, and the range of treatment options currently available reflects this bias. However, it is now understood that roughly one-half of all infertility cases are due to male-specific factors. ${ }^{3}$ Many cases of male infertility are idiopathic, but known causes of male infertility include pregonadal endocrine, genetic, or coital disorders; gonadal dysfunction involving spermatogenesis arrest, cryptorchidism, or varicocele; and postgonadal problems, including sperm blockage or genital infection. ${ }^{4,5}$

\begin{abstract}
Male factors, including those of autoimmune origin, contribute to approximately $50 \%$ of infertility cases in humans. However, the mechanisms underlying autoimmune male infertility are poorly understood. Deficiency in autoimmune regulator (AIRE) impairs central immune tolerance because of diminished expression of self-antigens in the thymus. Humans with AIRE mutations and mice with engineered ablation of Aire develop multiorgan autoimmunity and infertility. To determine the immune targets contributing to infertility in male Aire-deficient ${\left({ }^{-/}\right) \text {mice, Aire }}^{-/-}$or wild-type (WT) males were paired with WT females. Aire ${ }^{-/-}$males exhibited dramatically reduced mating frequency and fertility, hypogonadism, and reduced serum testosterone. Approximately 15\% of mice exhibited lymmitotically active germ cells; the remaining mice showed normal testicular morphology, sperm counts, and motility. However, spermatozoa from all Aire ${ }^{-/-}$mice were defective in their ability to fertilize WT oocytes in vitro. Lymphocytic infiltration into the epididymis, seminal vesicle, and prostate gland was evident. Aire ${ }^{-1}$ male mice generated autoreactive antibodies in an age-dependent manner against sperm, testis, epididymis, prostate gland, and seminal vesicle. Finally, expression of Aire was evident in the seminiferous epithelium in an age-dependent manner, as well as in the prostate gland. These findings suggest that Aire-dependent central tolerance plays a critical role in maintaining male fertility by stemming autoimmunity against multiple reproductiv
\end{abstract}

The immune system is responsible for controlling the potentially damaging influence of infections, while maintaining tolerance to self-antigens. Failure of the latter manifests as autoimmune disease, often involving complex genetic and environmental interactions. ${ }^{6}$ As many as $10 \%$ of

\footnotetext{
Supported by NIH grants R21 HD062879 and R01 HD100832 (M.G.P.), Michigan State University, Michigan State University AgBioResearch, the Kansas IDeA Network for Biomedical Research Excellence P20RR016475, and the University of Kansas Medical Center Biomedical Research Training Grant Program (B.D.W.).

Disclosures: None declared.
} 
the known causes of male-factor infertility involve immune conditions, which include orchitis, epididymitis, and autoantibody targeting. ${ }^{7}$ Thus, infection or damage to the male reproductive tract can result in immune targeting of antigens unique to germ cells, seminiferous epithelium, the epididymis, and/or the vas deferens.

Monogenic autoimmune diseases, which result from single-gene deficiencies, are rare, but have provided insight into the mechanisms of establishment and breakdown of self-discrimination/non-self-discrimination. ${ }^{10}$ Autoimmune polyendocrine syndrome type I (APS-1) is one such disease that results from function-disrupting mutations in the autoimmune regulator (AIRE) gene. ${ }^{11,12}$ APS-1 is characterized by high serum titers of autoantibodies and is diagnosed on the basis of the presence of two of three pathologies of principle targets: adrenal insufficiency, chronic mucocutaneous candidiasis, and hypoparathyroidism. ${ }^{13-15}$ APS-1 also targets other systems, including male and female reproductive organs, often leaving patients infertile. ${ }^{14}$

AIRE is a $58-\mathrm{kDa}$ nuclear glycoprotein that is most prominently expressed in medullary thymic epithelial cells (mTECs) and possesses structural and functional attributes suggestive of a transcription factor. ${ }^{16,17}$ AIRE has a vital role in establishing central immune tolerance by virtue of its ability to induce promiscuous expression of numerous antigens in mTEC that are otherwise restricted to one or a few other tissues. ${ }^{17}$ This occurs, in part, through one of AIRE's two plant homeodomain motifs, which targets AIRE to genes with histone markers typical of transcriptionally inactive genes. ${ }^{18-20}$ Once expressed, these antigens are processed and presented in the context of surface major histocompatibility molecules, either directly by thymic epithelial cells or indirectly via cross-presentation by thymic dendritic cells. T cells encountering these antigens via their cognate $\mathrm{T}$-cell receptors are either directed toward the regulatory T-cell lineage or deleted and thereby prevented from entering the periphery where they may otherwise cause autoimmune disease. ${ }^{21-24}$

In mice, targeted deletion of Aire (Aire ${ }^{-I-}$ ) reproduces many key features of APS-1. mTECs of Aire ${ }^{-l-}$ mice have a significantly altered self-antigen expression profile, which allows inappropriate development and emigration of selfreactive $\mathrm{T}$ cells from the thymus and culminates in destructive autoimmune response mediated by $\mathrm{T}$ cells and serum autoantibodies. ${ }^{17,25-27}$ In addition, disease onset and severity are highly variable both within and between genetic backgrounds. ${ }^{28}$ Among Aire-regulated antigens are those found within, and even exclusive to, the male reproductive system. ${ }^{18}$ Interestingly, several authors have noted reduced fertility in male Aire ${ }^{-l-}$ mice, as well as autoimmune prostatitis. ${ }^{17,25-27,29}$ However, the lesion leading to infertility in male Aire $^{-1-}$ mice has not been completely identified. In the present study, the consequence of a disruption of Aire in male mice for fertility were explored, examined in the potential targets of autoimmune disease of the male reproductive tract were examined in detail, and expression of the Aire gene was assessed in key reproductive tract organs.

\section{Materials and Methods}

\section{Animals}

Mice were housed under pathogen-free conditions under a 12-hour light:12-hour dark photoperiod at the University of Kansas Medical Center or Michigan State University Campus Animal Resources and were provided with sterile food and water ad libitum. Experiments with animals complied with NIH's Guide for the Care and Use of Laboratory Animals ${ }^{30}$ and were approved by the Institutional Animal Care and Use Committee at University of Kansas Medical Center and Michigan State University. Recombinase activating gene $2(\operatorname{Rag} 2)-$ deficient mice $\left[\operatorname{Rag} 2^{-1-}\right.$; C.129S6(B6)-Rag2 ${ }^{\text {tm1Fwa }}$ ] were purchased from Taconic (Rensselaer, NY). Aire ${ }^{-1-}$ mice on the Balb/cJ genetic background (more than eight generations) ${ }^{17,28}$ were donated by Christophe Benoist (Harvard Medical School, Boston, MA), and were maintained by breeding heterozygotes. Gt(ROSA)26Sor tm4(ACTB-tdTomato,-EGFP)Luo $/ J\left(\mathrm{mTmG}^{31}\right.$ and Balb/cJ wild-type (WT) mice were purchased from The Jackson Laboratory (Bar Harbor, ME). Aire-Cre mice were generated as described, ${ }^{32}$ and genotypes for all mice were determined by PCR, as previously described. ${ }^{32-34}$

\section{Fertility Assessment}

Fertility was evaluated in 6- to 13-week-old Aire ${ }^{-1-}$ males and WT controls. WT or Aire ${ }^{-1-}$ males were cohabitated singly with WT females (6 to 10 weeks old), which were checked each morning until a copulation plug was detected, at which time the male was euthanized for blood and tissue collection. The females were allowed 23 days postcopulation to deliver pups, and the offspring were counted if a litter was produced. If a copulation plug was not visually confirmed over a period of 20 days (approximately four ovarian cycles), the male was euthanized, and the female was permitted 21 days of isolation to verify absence of pregnancy before being mated to a proven WT BALB/c male to confirm the female's fertility.

\section{Blood and Tissue Collection}

Mice were anesthetized with a sterile solution of Avertin (2,2,2-tribromoethanol dissolved in 2-methyl-2-butanol; 250 $\mathrm{mg} / \mathrm{kg}$ intraperitoneally; Sigma-Aldrich, St. Louis, MO). Serum was collected under anesthesia via cardiac puncture, after which mice were euthanized via cervical dislocation and bilateral pneumothorax. Testis, epididymis, seminal vesicles, and prostate gland were removed and weighed, fixed in $4 \%$ paraformaldehyde overnight, and embedded in paraffin for histopathologic analysis. 


\section{Determination of Serum Hormone Levels}

Serum follicle-stimulating hormone (FSH), luteinizing hormone (LH), and testosterone were measured at the University of Virginia Center for Research in Reproduction Ligand Assay and Analysis Core (Charlottesville, VA). FSH and testosterone were quantified by radioimmunoassay, with ranges of 2.0 to $25 \mathrm{ng} / \mathrm{mL}$ and 0.1 to $10 \mathrm{ng} / \mathrm{mL}$, respectively. LH was measured by sandwich radioimmunoassay, with an assay range of 0.07 to $37.4 \mathrm{ng} / \mathrm{mL}$. CVs for the assays were as follows: FSH, 6.9\% (intra-assay) and 9.4\% (interassay); LH, $4.5 \%$ (intra-assay) and $8.3 \%$ (interassay); and testosterone, $4.7 \%$ (intra-assay) and $8.5 \%$ (interassay). Standards for the assays included a reference preparation of mouse LH (AFP5306A) and FSH (AFP5308D); further details of all assays performed are available (https://med. virginia.edu/research-in-reproduction/ligand-assay-analysiscore, last accessed May 18, 2021).

\section{Caudal Sperm Production and Analysis}

Caudal epididymides were excised from mice following sacrifice, rinsed, weighed, and transferred to $750 \mu \mathrm{L}$ of Human Tubal Fluid media (EMD Millipore, Burlington, MA). The tissue was bisected, and sperm was allowed to exude for 1 hour at $37^{\circ} \mathrm{C}$. Sperm count was determined using a hemocytometer and normalized to the weight of the tissue.

\section{Sperm Motility Analysis}

Sperm motility analysis was performed as previously described. ${ }^{35}$ Briefly, $3 \times 10^{6}$ cells were resuspended in modified Tyrode medium containing $1.7 \mathrm{mmol} / \mathrm{L} \mathrm{CaCl}_{2}$. The cells were labeled with the green fluorescent nucleic acid stain SITO21 and loaded onto glass cell chambers (Leja Products BV, Nieuw-Vennep, the Netherlands). The chambers were viewed using an Olympus BX51 microscope (Olympus, Feasterville, PA) while being maintained at $37^{\circ} \mathrm{C}$ on a heated platform. Samples were analyzed by computerassisted sperm analysis using the Minitube SpermVision Digital Semen Evaluation system version 3.5 (Penetrating Innovations, Verona, WI). Sperm motility parameters, including total and progressive motility, were measured.

\section{Sperm Production Analysis}

Daily sperm production (DSP) was determined as previously described. ${ }^{36}$ One testis was frozen in liquid nitrogen and stored at $-80^{\circ} \mathrm{C}$ until analysis. To determine DSP, testes were thawed, decapsulated, weighed, and dissolved in $1 \mathrm{~mL}$ saline containing $0.01 \%$ Triton $\mathrm{X}-100$ by homogenization (Tissue-Tearor, model 985370-395; BioSpec Products Inc., Bartlesville, OK) at 15,000 rpm for 3 minutes. Elongated spermatids (stages 14 to 16), which are resistant to homogenization, were counted by trypan blue dye staining on a hemocytometer. Total spermatid number per testes was divided by weight of the decapsulated testis to give spermatids per gram of testis. Developing mouse spermatids spend approximately 4.84 days in steps 14 to 16 during spermatogenesis. ${ }^{37}$ Thus, the values for spermatids/ testis and spermatids per gram testis were divided by 4.84 to obtain the DSP and efficiency (DSP per gram) of sperm production, respectively.

\section{Histopathologic Evaluation and Immunohistochemistry}

Paraformaldehyde-fixed, paraffin-embedded reproductive tract tissues were sectioned at a thickness of $5 \mu \mathrm{m}$ and stained with hematoxylin and eosin (Dako, Santa Clara, CA). Immunohistochemistry was used for the detection of CD3-positive and MKI67 (Ki-67)-positive cells within the tissues of the male reproductive tract of Aire ${ }^{-1-}$ and WT controls. To this end, sections were rehydrated through decreasing concentrations of ethanol and, for CD3 and Ki67 staining, subjected to antigen retrieval using Reveal buffer (BioCare Medical, Pacheco, CA). Tissue sections were then blocked in $10 \%$ goat serum and incubated overnight at $4{ }^{\circ} \mathrm{C}$ with monoclonal rabbit anti-mouse $\mathrm{CD} 3$ (clone SP7; 1:100 dilution of neat supernatant; Abcam, Cambridge, UK) or rabbit anti-human Ki-67 (clone SP6; 1:200 dilution of supernatant; Thermo Fisher, Waltham, MA). The SP7 antibody recognizes the $\mathrm{CD} 3 \varepsilon$ chain of the $\mathrm{CD} 3$ complex on $\mathrm{T}$ cells and has been validated by the manufacturer via Western blot analysis, flow cytometry, and immunohistochemistry using $\mathrm{CD}^{+}{ }^{+} \mathrm{T}$-cell lines. The Ki-67 antibody has been validated by the manufacturer using cell starvation/ replacement treatment and by analysis of knockout cells. In our experiments, isotype-matched rabbit IgG (Jackson ImmunoResearch, West Grove, PA) was used as a negative control. Sections were incubated with biotinylated goat antirabbit IgG (Vector Laboratories, Burlingame, CA; catalog number BA-1000), and subsequently depleted of endogenous peroxidases. For colorimetric detection of bound antibodies, streptavidin peroxidase and aminoethyl carbazole were added to the sections, producing a red-brown deposit (Invitrogen, Carlsbad, CA). Sections were counterstained with hematoxylin and viewed by bright-field microscopy on a Nikon 80i microscope (Nikon, Melville, NY). To assess mean numbers of mitotically active germ cells in seminiferous tubules, testis sections were stained for $\mathrm{Ki}-67$. Ki67-positive cells were counted in five random fields at $\times 200$ magnification. Data collected included the average numbers of Ki-67-positive cells per tubule, as well as the overall proportion of tubules that contained Ki-67-positive cells.

\section{Immunoblotting}

WT and Aire ${ }^{-l-}$ mouse sera were used to probe testis, caput, cauda, seminal vesicle, prostate, and sperm lysates 
from $\mathrm{Rag} 2^{-1-}$ mice for the presence of autoantibodies. Tissue was homogenized on ice in radioimmunoprecipitation assay buffer and boiled for 5 minutes in reducing buffer. Tissue lysate $(400 \mu \mathrm{g})$ was run on a $4 \%$ to $20 \%$ TGX stain-free curtain gel (BioRad, Hercules, CA) and transferred to a nitrocellulose membrane (GE Healthcare Life Sciences, Chicago, IL) at $100 \mathrm{~V}$ for 20 minutes. The membrane was blocked for 3 hours at room temperature in $3.5 \%$ bovine serum albumin in phosphate-buffered saline before being placed inside a Mini-Protean II Multiscreen apparatus (BioRad). Sera (1:750 dilution) from WT and Aire $^{-1-}$ mice were loaded into the slots and incubated at $4{ }^{\circ} \mathrm{C}$ overnight. Membranes were washed in phosphatebuffered saline containing $0.1 \%$ Tween 20 and incubated with a horseradish peroxidase-conjugated anti-mouse secondary antibody (Sigma-Aldrich). Immunoreactivity was visualized using an ECL detection kit (GE Healthcare Life Sciences), according to the manufacturer's instructions.

\section{Immunofluorescence}

Cellular reactivity with serum autoantibodies was determined by immunofluorescence using sera from Aire ${ }^{-1-}$ mice to probe testis, epididymis, seminal vesicles, and prostate glands of Rag2 ${ }^{-l-}$ mice. Briefly, tissues were flash frozen in dry ice-cooled 2-methylbutane (Sigma-Aldrich) for 5 minutes before embedding in OCT cryoprotective medium (Sakura Finetek, Torrance, CA). Sections were cryosectioned (10 $\mu \mathrm{m}$ thick) and fixed in $100 \%$ cold acetone for 5 minutes. Serum from WT and Aire ${ }^{-l-}$ mice was added at a 1:40 dilution, and bound antibodies were visualized using a goat anti-mouse IgG fluorescein isothiocyanate-conjugated secondary antibody (Jackson ImmunoResearch). To determine whether endogenous autoantibodies were bound within the cauda epididymis, fluorescein isothiocyanate-labeled goat anti-mouse $\mathrm{IgG}$ antibody was applied directly onto cryosections from WT and Aire ${ }^{-1-}$ mice. All sections were coverslipped using Prolong Gold containing DAPI (Invitrogen) and viewed on a Nikon 80i fluorescent microscope.

Expression of Aire in the reproductive tract was evaluated, as previously described, ${ }^{33}$ using a commercially available primary antibody (rat anti-mouse Aire; clone $5 \mathrm{H} 12 ; 5 \mu \mathrm{g} / \mathrm{mL}$; Thermo Fisher). Specificity of this antibody was confirmed by us previously ${ }^{33}$ using thymus tissue from WT and Aire ${ }^{-/-}$mice as positive and negative controls, respectively. WT males were euthanized at 3 and 12 weeks of age, and testis, epididymis, prostate, and seminal vesicles were fixed in $4 \%$ paraformaldehyde, cryopreserved in $30 \%$ sucrose, and frozen in OCT embedding medium. Tissues were sectioned at $5 \mu \mathrm{m}$ thickness, permeabilized with $0.1 \%$ Triton $\mathrm{X}-100$, and blocked in $10 \%$ goat serum. Sections were then incubated in primary antibody at $4{ }^{\circ} \mathrm{C}$ overnight, washed, and incubated with goat anti-rat secondary antibody conjugated to Alexa Fluor $488(10 \mu \mathrm{g} / \mathrm{mL}$; Thermo Fisher; catalog number A11006). Sections were counterstained with DAPI (Vector Laboratories) and imaged as above.

\section{In Vitro Fertilization}

Female WT mice were given pregnant mare's serum gonadotropin (5 IU/mL intraperitoneally), followed by human chorionic gonadotropin (5 IU/mL intraperitoneally) 48 hours later. Twelve hours after human chorionic gonadotropin injection, the mice were sacrificed and the oocytes were flushed from the oviduct, washed through three microdrops of FHM-HEPES (EMD Millipore), and placed in a culture dish with Human Tubal Fluid media. To collect sperm, WT or Aire ${ }^{-1-}$ males were sacrificed on the same day as oocyte collection, and caudal epididymis was dissected and incubated at $37^{\circ} \mathrm{C}$ in $1 \mathrm{~mL}$ of Human Tubal
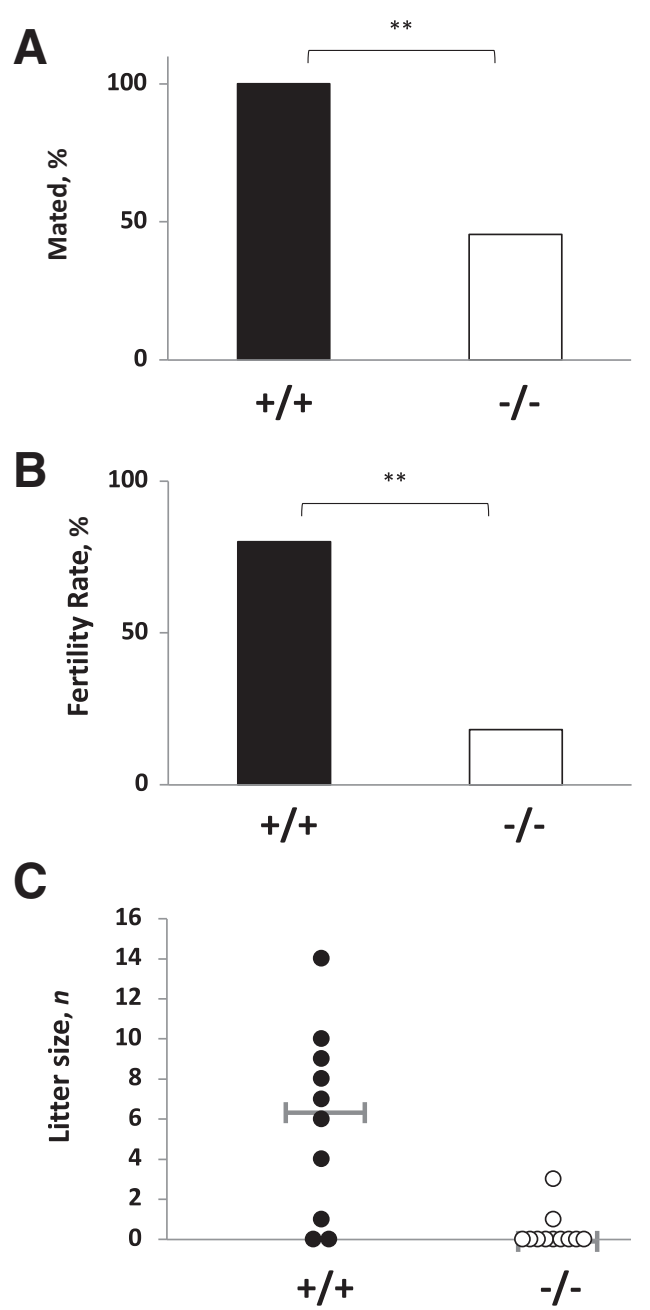

Figure 1 Fertility parameters in Aire ${ }^{-/-}$male mice. Wild-type (WT) control $(+/+)$ and Aire ${ }^{-/-}$male mice were paired with $+/+$females, which were monitored for copulation plugs for up to 21 days. A: Percentage of $+/+$ controls and Aire ${ }^{-/-}$males that produced a copulatory plug. B: Percentage of $+/+$ and Aire $^{-/-}$males that generated viable litters. C: Numbers of offspring produced by $+/+$ and Aire ${ }^{-/-}$males. Each data point represents the litter size of an individual male; gray horizontal bars represent means. $n=10$ WT mice $(\mathbf{A}-\mathbf{C}) ; n=11$ Aire $^{-/-}$mice $(\mathbf{A}-\mathbf{C}) .{ }^{* *} P<0.01$. 
Fluid for at least 90 minutes. Capacitated sperm ( 1 to $2 \times$ $10^{6}$ ) was incubated with collected oocytes at $37^{\circ} \mathrm{C}$ for an additional 4 to 6 hours. Oocytes were then washed and cultured in microdrops of potassium-supplemented simplexoptimized medium (KSOM) with amino acids and D-glucose (EMD Millipore). Embryos were visualized and staged using an inverted light microscope 24 and 96 hours after fertilization.

\section{Bioinformatic Identification of Testis-Specific Aire Target Genes}

To identify tissue-specific gene sets, we combined the genome-wide RNA-sequencing data from two previous studies that cover 47 diverse tissues, including testis, thymus, uterus, brain, adrenal gland, liver, placenta, ovary, and kidney. ${ }^{38,39}$ Quantile normalization was applied to normalize the data across different samples and remove potential confounding factors. This was followed by hierarchical clustering to visualize clusters of tissue-specific genes. To remove housekeeping genes, the entropy of expression values for each gene across the samples was calculated and ranked. Only the top 50\% genes with small entropy values were included in the downstream analyses. For each of these, the z-scores of the gene's expression in each tissue were calculated and $\mathrm{z}$-scores of $>2.5$ were defined as tissue-specific.

To identify Aire target genes, the published RNAsequencing data from various populations of murine thymic epithelial cells was used. ${ }^{40}$ Two versions of target genes were generated. For the first, gene expression was compared in Aire ${ }^{-1-}$ versus wild-type mTECs. For the second, gene expression was compared in Aire mRNAnegative versus Aire mRNA-positive mTECs, which were identified bioinformatically on the basis of known TEC markers as well as Aire mRNA expression. For differential gene expression analysis, two criteria were used: subtraction of $\log _{2}$-transformed fragments per kilobase of transcript per million mapped reads values from the two conditions in comparison and fold change of $\log _{2}$-transformed fragments per kilobase of transcript per million mapped reads values. The genes were then ranked from largest to smallest value
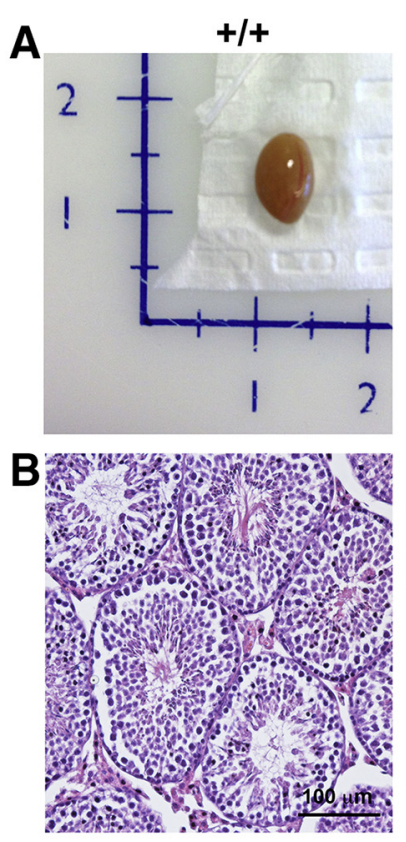

C

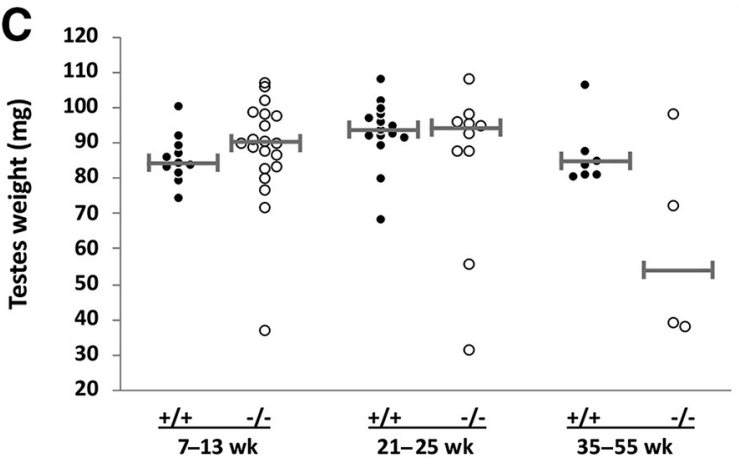

$-1-$
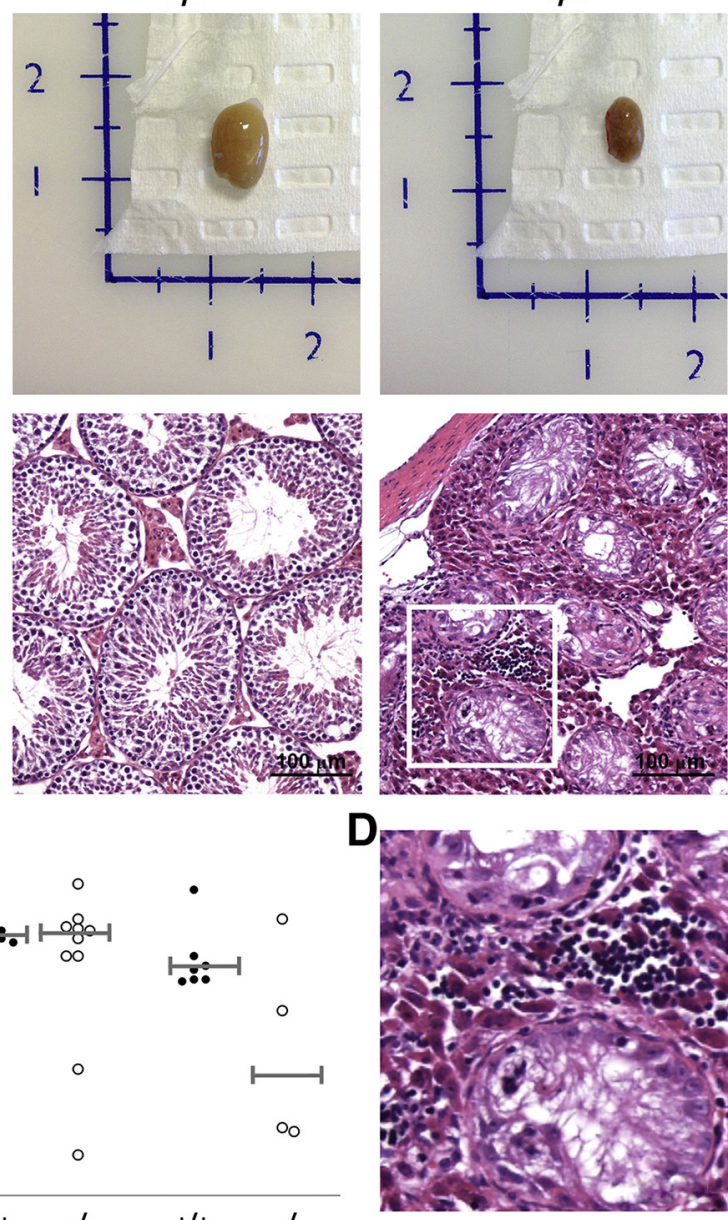
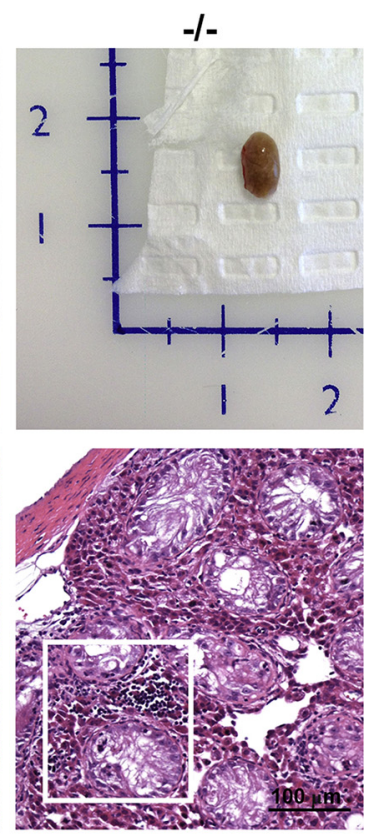

Figure 2 Testicular atrophy and lymphocytic infiltration occur in a subset of Aire ${ }^{-/-}$mice. A: Representative examples of testes from wild-type (WT; left panel) and Aire ${ }^{-/-}$(middle and right panels) mice. B: Histologic analysis of WT (left panel) and Aire $^{-/-}$(middle and right panels) testis, showing lymphocytic infiltrate and interstitial cells. C: Testis weight in $+/+$ and Aire ${ }^{-/-}$ mice. Each data point represents an individual animal; gray horizontal bars represent the mean. Weights of testis were recorded for 34 WT and 34 Aire $^{-/-}$mice. D: Enlarged view of lymphocytic infiltrate, boxed area in B. $n=17$ WT testis (B); $n=23$ Aire $^{-/-}$testis (B). Scale bars $=100 \mu \mathrm{m}$ (B and D). 


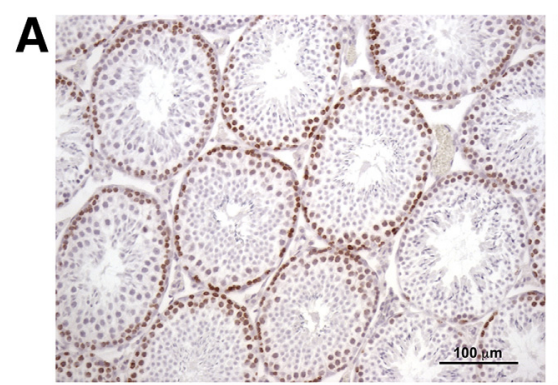

B

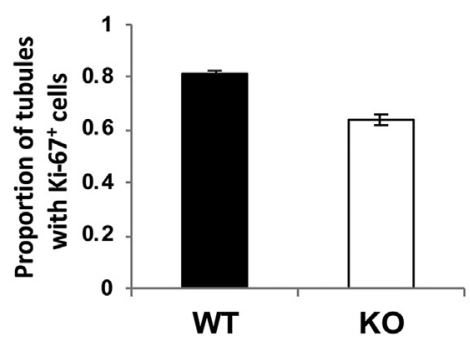

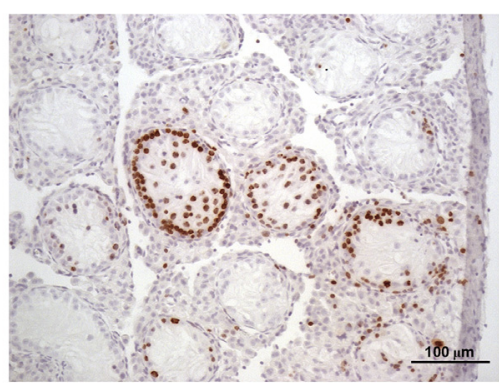

C

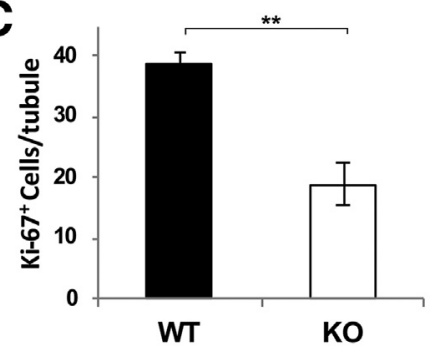

Figure 3 Disruption of seminiferous tubule organization in Aire ${ }^{-/-}$mice. A: Representative images comparing Ki-67 immunoreactivity in testis of wild-type (WT) and Aire $^{-/-}$males. B: The proportion of seminiferous tubules containing proliferative $\left(\mathrm{Ki}-67^{+}\right.$) germ cells in WT and Aire ${ }^{-1-}$ testis, as evaluated by immunohistochemistry. C: $\mathrm{Ki}-67^{+}$germ cells per tubule from immunohistochemical stains of WT and Aire ${ }^{-/-}$mice. Data are given as means \pm SEM (B and C). $n=3$ WT males (A); $n=5$ Aire $^{-/-}$males (A). ${ }^{* *} P<0.01$. Scale bars $=100 \mu \mathrm{m}$. $\mathrm{K} 0$, knockout. based on the two metrics separately, and those ranked at the top $10 \%$ on both metrics were considered as down-regulated target genes by Aire, whereas those ranked at the bottom $10 \%$ on both metrics are considered as up-regulated targets. The Aire target genes were then compared with different sets of tissue-specific genes to identify tissue-specific Aire target genes, using hypergeometric tests to determine the statistical significance of the overlap between Aire target genes and tissue-specific genes. The overrepresentation of Aire target genes in different tissues was then quantified by $-\log _{10}(P$ value $)$. Finally, Gene Ontology and pathway enrichment analysis ${ }^{41}$ were performed using David Gene Functional Annotation tool. ${ }^{42}$ The top enriched pathways were used to analyze the potential functional roles of tissuespecific Aire target genes.

\section{Aire Gene Expression in Male Reproductive Tract Tissues}

Aire gene expression was evaluated by two methods: quantitative RT-PCR (RT-qPCR) and reporter gene analysis. For mRNA analysis, testis, epididymis, prostate, and seminal vesicles were harvested from 3- and 12-week-old WT males, frozen in liquid nitrogen, and processed for RNA extraction using TRIzol. In brief, frozen tissues were lysed with $1 \mathrm{~mL}$ of TRIzol using Omni Bead Ruptor 4 (Omni
A

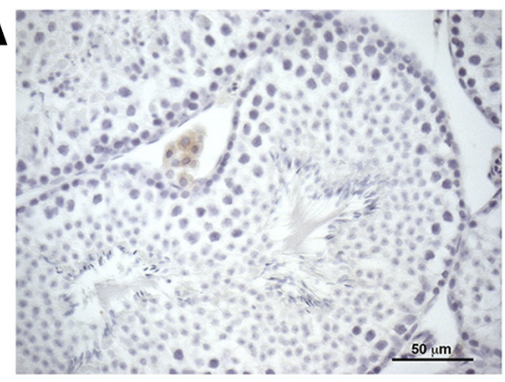

B

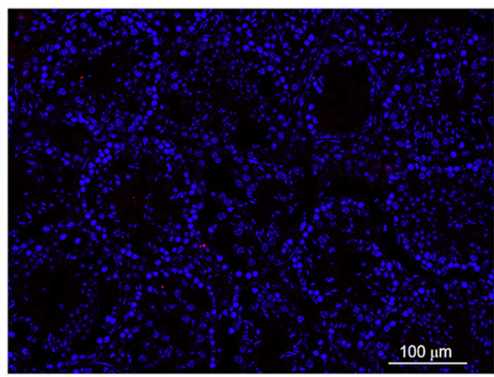

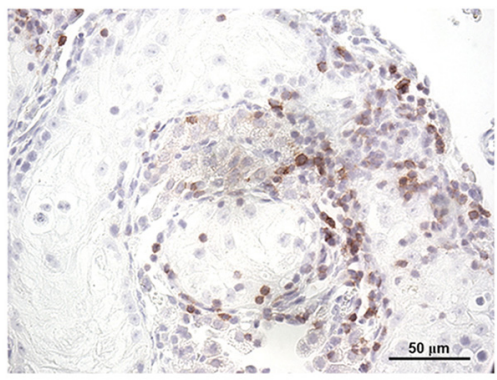

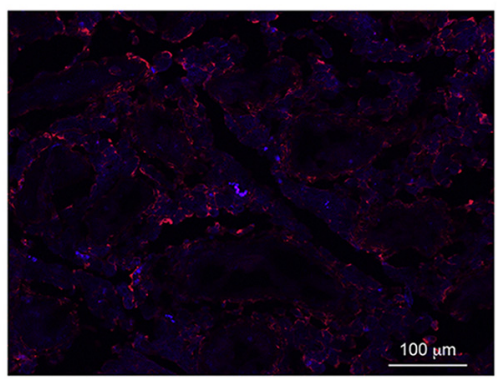

Figure 4 Immune cell infiltration into testes of Aire $^{-1-}$ mice. A: Representative sections of wild-type (WT; left panel) and Aire ${ }^{-/-}$(right panel) testes stained with anti-CD3 antibody. B: Representative sections of WT (left panel) and Aire $^{-/-}$(right panel) testes stained with antiF4/80 (macrophages) antibody. $n=7$ WT testes (A); $n=20$ Aire $^{-/-}$testes (A); $n=3$ WT testes (B); $n=5$ Aire $^{-/-}$testes (B). Scale bars: $50 \mu \mathrm{m}$ (A); $100 \mu \mathrm{m}$ (B). 

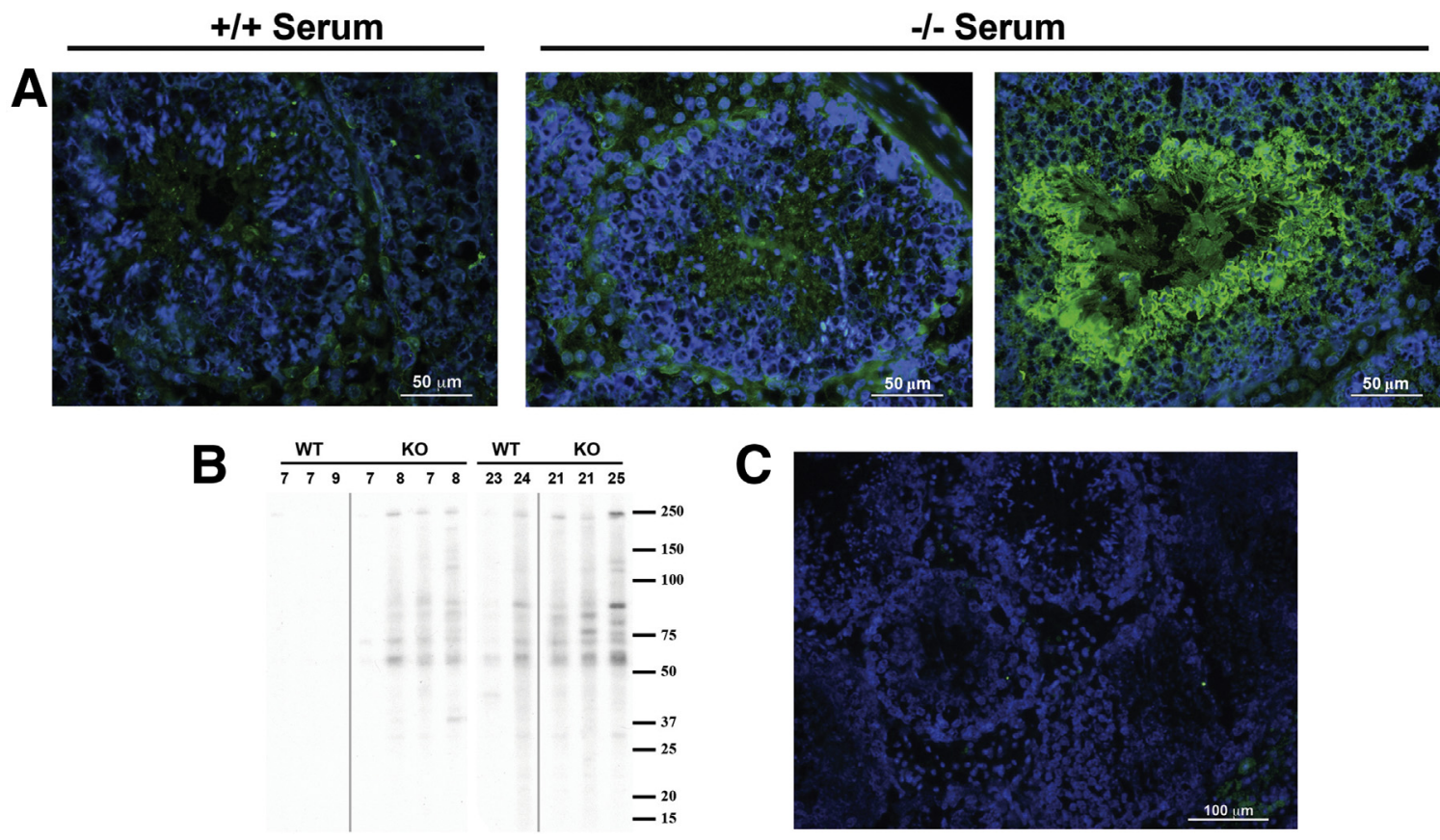

Figure 5 Identification of anti-testes autoantibodies in Aire ${ }^{-/-}$mice. A: Indirect immunofluorescence of Rag2 $2^{-/-}$testes cryosections, probed with serum from wild-type (WT) or Aire $e^{-1-}$ mice, followed by a fluorescently labeled anti-mouse secondary antibody. Representative sections are shown. B: Testicular lysate from a $\operatorname{Rag}^{-{ }^{-}-}$mouse was probed with serum samples from WT and Aire ${ }^{-/-}$mice. Each lane represents an individual mouse; ages in weeks are indicated at the top. Numbers on right, molecular weight marker $(\mathrm{kDa})$. C: Direct immunofluorescence of testis from an Aire ${ }^{-1-}$ mouse, using a fluorescently labeled antimouse IgG antibody to detect endogenously bound autoantibodies. A representative section is shown. $n=5$ WT mice $(\mathbf{A}) ; n=12$ Aire ${ }^{-/-}$mice $(\mathbf{A}) ; n=3$ (C). Scale bars: $50 \mu \mathrm{m}(\mathbf{A}) ; 100 \mu \mathrm{m}$ (C). K0, knockout.

International, Kennesaw, GA), then transferred into a phaselock tube. A total of $0.2 \mathrm{~mL}$ of chloroform was directly added, followed by 10 minutes of centrifugation at 12,000 $\times g$. The resulting colorless upper aqueous phase was carefully transferred into a new 1.5-mL Eppendorf tube and washed with $0.5 \mathrm{~mL}$ of isopropyl alcohol and $1 \mathrm{~mL} 75 \%$ ethanol. Resulting RNA pellet was dissolved in RNase-free water, assessed for 260/280 ratio using Nanodrop, and then
A

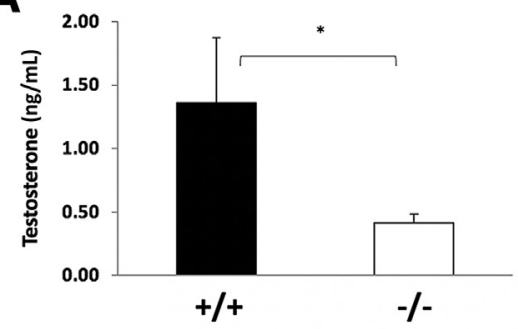

C

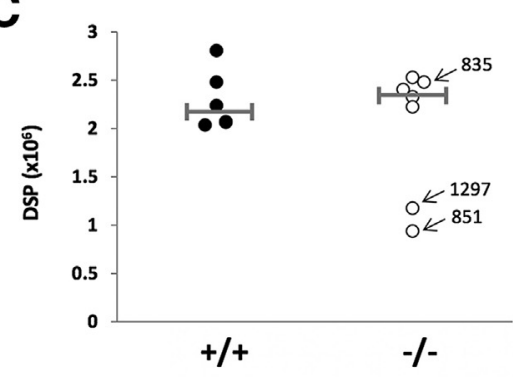

B

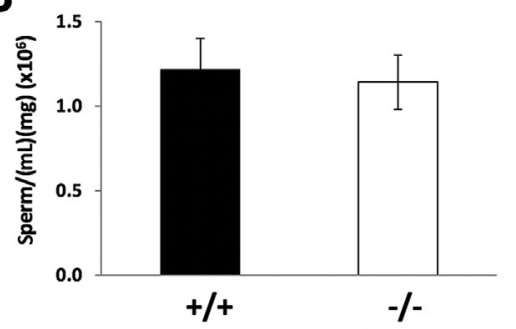

D

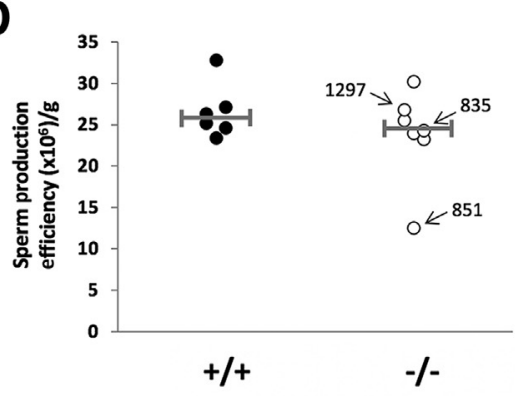

E

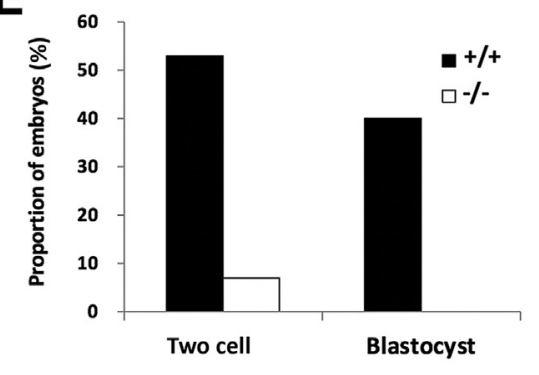

Figure 6 Reduced testosterone and oligospermia in a subset of Aire ${ }^{-/-}$mice. A: Serum samples from wild-type (WT) and Aire $e^{-/-}$mice were evaluated for testosterone. B: Capacitated epididymal sperm were measured by swim-out assay, and adjusted by caudal weight, of WT and Aire ${ }^{-1-}$ mice. C and D: Daily sperm production (DSP; ) and sperm production efficiency (D), as measured per gram testis weight, in WT and Aire ${ }^{-/-}$mice. $\mathbf{C}$ and $\mathbf{D}$ : Each data point represents an individual mouse, and numbers highlight individual mice of interest. E: Proportion of wild-type oocytes that developed to the two-cell and blastocyst stages following in vitro fertilization with sperm from WT $(+/+)$ or Aire ${ }^{-/-}$males. Data represent means \pm SEM $(\mathbf{A}$ and $\mathbf{B}) . n=8$ WT mice $(\mathbf{A}) ; n=14$ Aire ${ }^{-/-}$mice (A and $\mathbf{B}) ; n=11$ WT mice (B); $n=83$ oocytes from WT males (E); $n=102$ oocytes from Aire ${ }^{-/-}$males (E); $n=4$ WT and Aire ${ }^{-/-}$males (E). *P< 0.05 . 

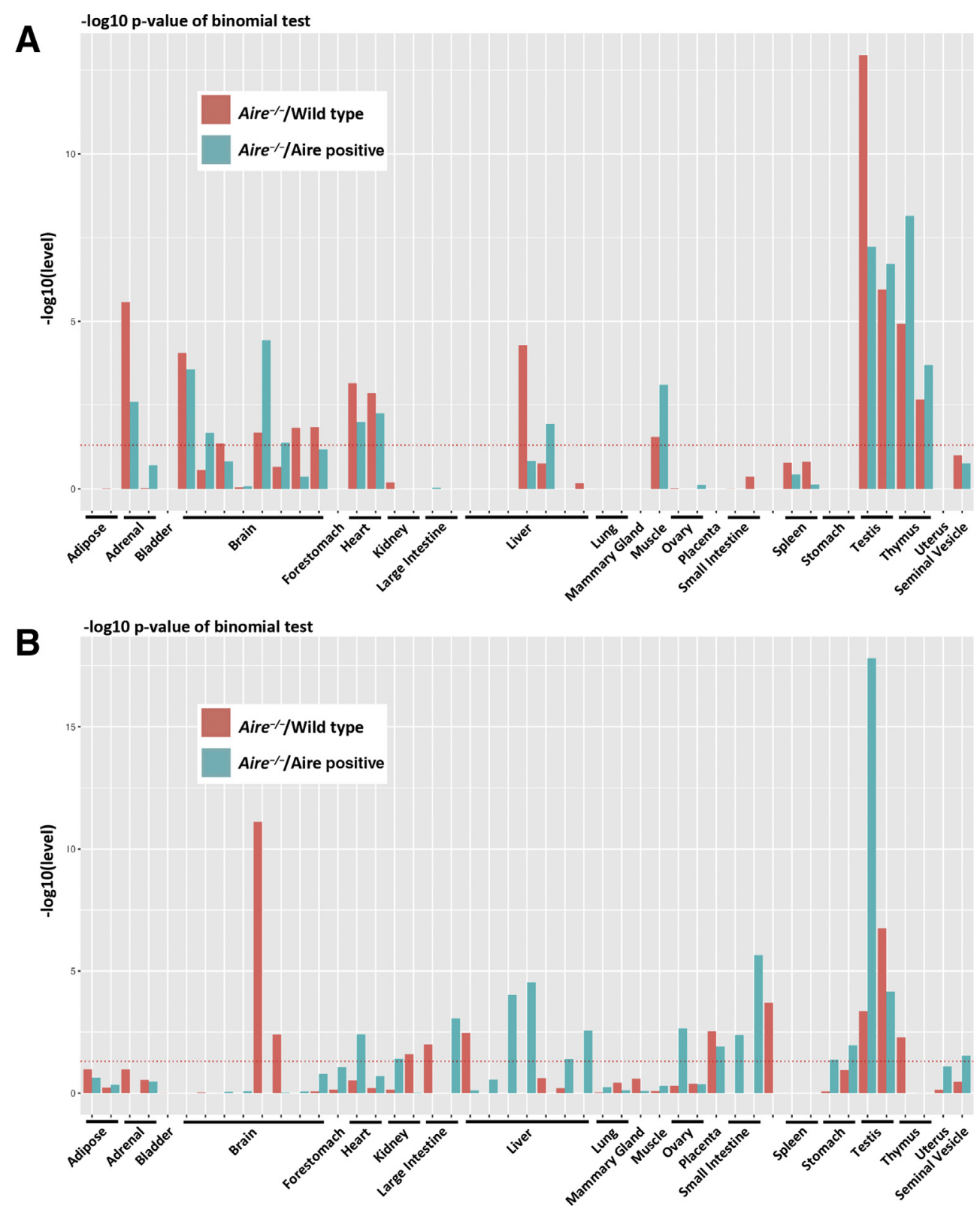

Figure 7 Overrepresentation of Aire target genes within tissue-specific gene sets. The hypergeometric test was used to calculate $P$ values to evaluate the enrichment of Aire target genes overlapping with tissue-specific gene sets across 47 tissues. A: Aire up-regulated genes. B: Aire down-regulated genes. The $y$ axis shows $-\log _{10}(P$ value $)$; and $x$ axis, 47 tissue-specific gene sets. Two versions of Aire target genes from: Aire ${ }^{-/-}$versus wild type (red) and Aire negative versus Aire positive (blue). The $y$-axis value of $1(P=0.1)$ is marked by the red dotted line.

converted to cDNA using Quantitect Reverse Transcription Kit (Qiagen, Germantown, MD); catalog number 205314), followed by real-time quantitative PCR (QuantStudio 5; Applied Biosystems, Waltham, MA). Samples were analyzed using the delta delta cycle threshold (ddCT) method for the relative expression of Aire mRNA (TaqMan Probe Assay ID: Mm00477452_g1). Gapdh (TaqMan Probe Assay ID: Mm99999915_g1) was used as a housekeeping control.

In addition to mRNA analysis, we generated a transgenic reporter system that indicates expression of Aire or a history thereof. mTmG mice ${ }^{31}$ express a fluorescent reporter construct that allows constitutive expression of membranetargeted tandem dimer Tomato (mT) in the absence of Cre recombinase. In the presence of Cre, the $\mathrm{mT}$ locus is excised, resulting in expression of membrane-enhanced green fluorescent protein (mG). $\mathrm{mTmG}$ females were mated with Aire-Cre males ${ }^{32}$ such that all fetuses were heterozygote for both the $m \operatorname{Tm} G$ and the Aire-Cre loci, and thus expressed $\mathrm{mG}$ in all Aire-expressing tissues. Aire-Cre/ $m T m G$ males were sacrificed at 3 and 9 weeks of age, and tissues were harvested, fixed, and sectioned. Sections were 


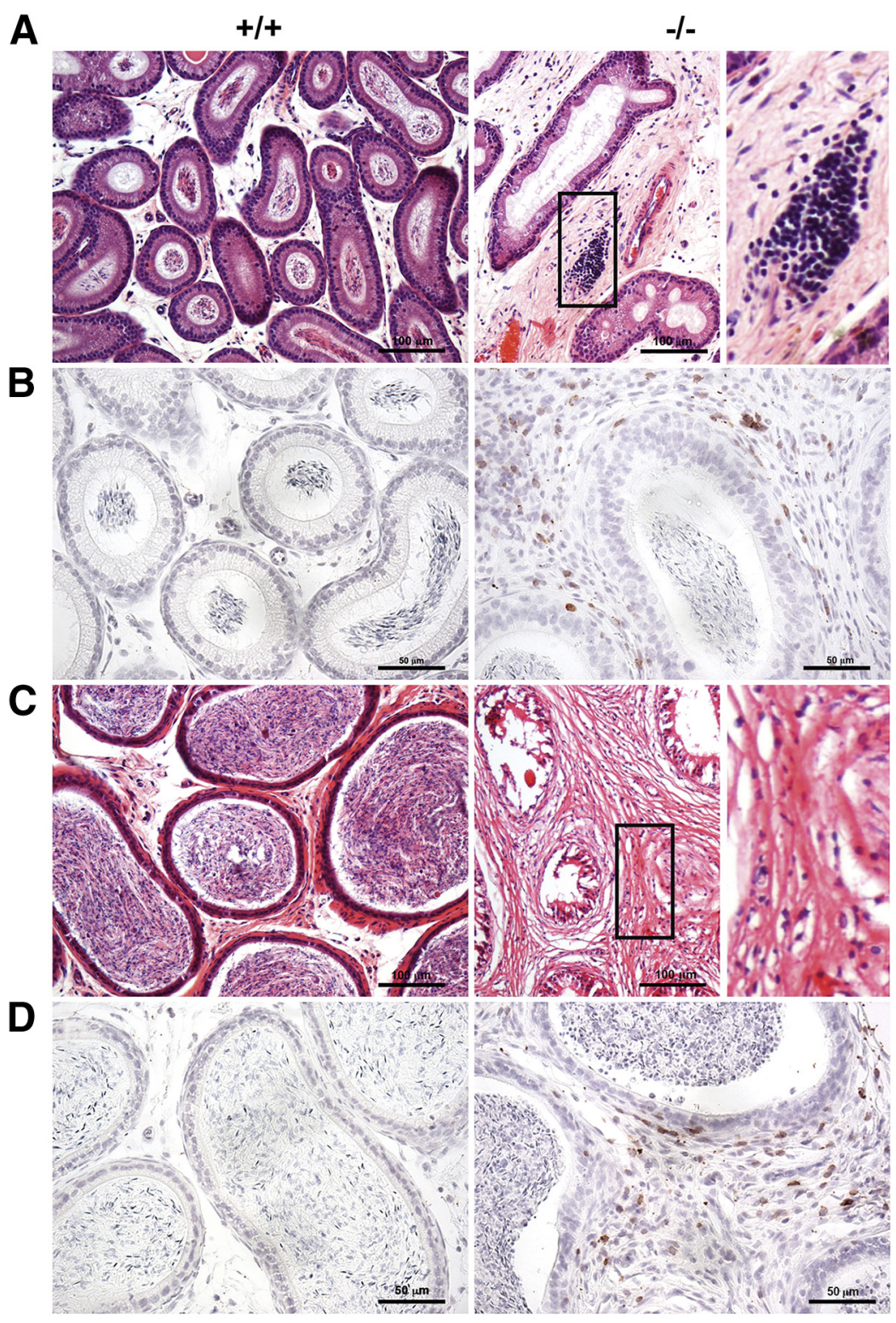

Figure 8 Histologic analysis of caput and cauda epididymis. Representative sections of caput (A and $\mathbf{B}$ ) and cauda (C and $\mathbf{D}$ ) epididymis were stained with hematoxylin and eosin (A and $\mathbf{C}$ ) or antibody against CD3 (B and $\mathbf{D})$. Boxed areas in $\mathbf{A}$ and $\mathbf{C}$ are shown at higher magnification to the right. $n=7$ wild-type animals (A-D); $n=20$ Aire $^{-/-}$animals (A-D). Scale bars: 100 $\mu \mathrm{m}$ (A and $\mathbf{C}) ; 50 \mu \mathrm{m}$ (B and $\mathbf{D})$.

coverslipped in medium containing DAPI and imaged on a Nikon Eclipse Ti epifluorescence microscope.

\section{Statistical Analysis}

Hormone values, caudal sperm count, $\mathrm{Ki}-67^{+}$cells per seminiferous tubule, and testis weights between WT controls and Aire ${ }^{-/-}$mice were analyzed by two-tailed $t$-test. Percentages of mice capable of mating and producing viable offspring and in vitro fertilization results were compared by $\chi^{2}$ analysis. Outliers in hormone data were identified in two (one WT and one Aire ${ }^{-l-}$ mouse) cases using the Grubbs test, and were excluded from analysis. Results were considered significantly different when
$P<0.05$. All statistical analyses were performed using SigmaStat version 3.5 (Systat, San Jose, CA). All experiments were repeated with a minimum of three biological replicates; $n$ is indicated in the appropriate locations for each experiment in the figure legends.

\section{Results}

\section{Assessment of Fertility in Male Aire ${ }^{-/-}$Mice}

To examine fertility, WT or Aire ${ }^{-1-}$ males were housed with WT females and monitored each morning for the presence of a copulatory plug. All 10 WT males produced a plug within 5 days of pairing with a female, 

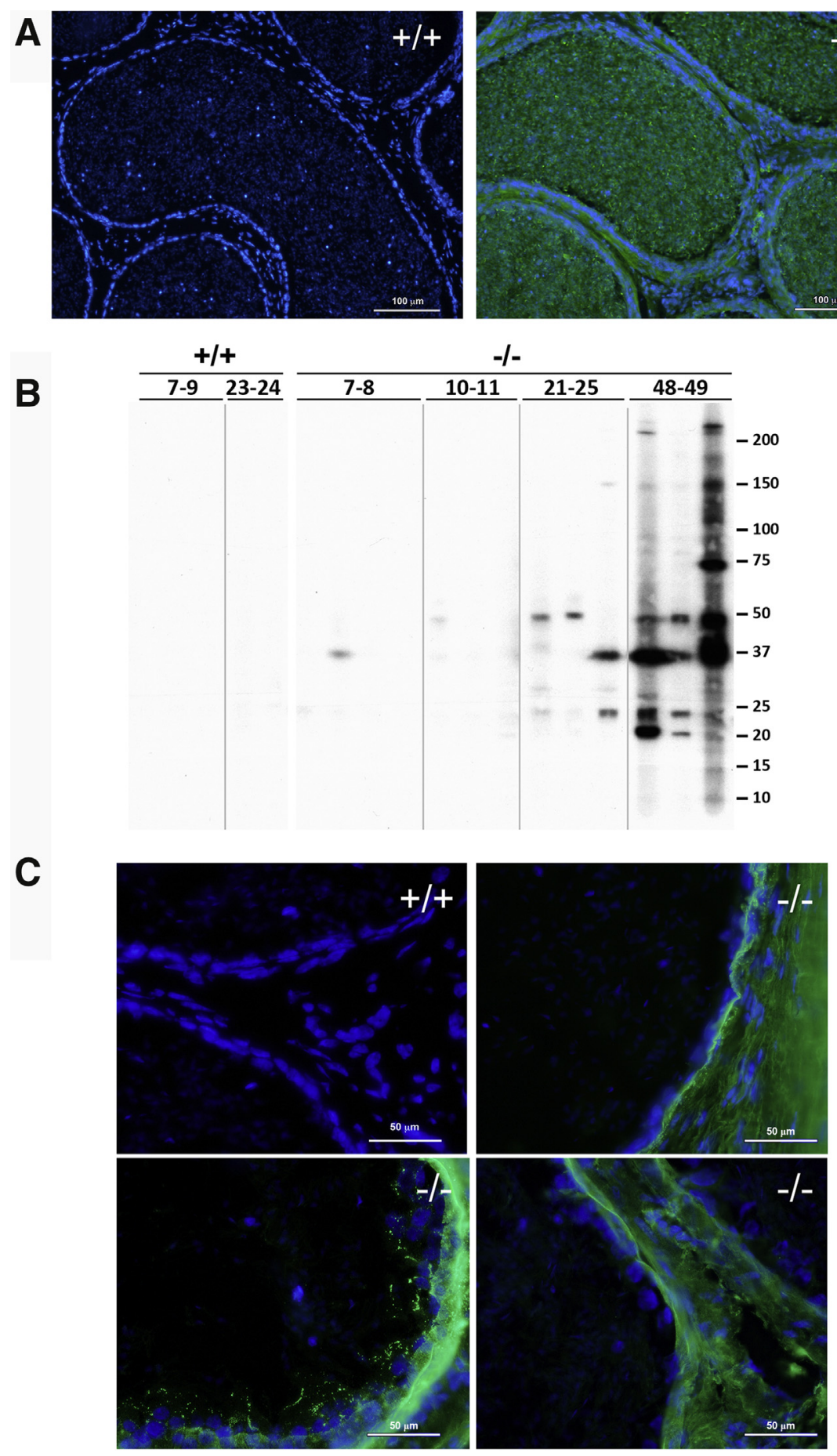

Figure 9 Antibody reactivity to epididymis in Aire $^{-/-}$mice. A: Serum from wild-type (WT) or Aire ${ }^{-/-}$ mice was applied to cryosections of epididymides of $\operatorname{Rag}^{-/-}$mice, which were subsequently probed with a fluorescein isothiocyanate (FITC)-labeled antimouse IgG secondary antibody. B: Epididymal lysate from a Rag2 $^{-1-}$ mouse was probed with sera from WT and Aire $^{-1-}$ mice. Each lane represents an individual mouse; ages in weeks are indicated at the top, and numbers on right represent the molecular weight marker (kDa). C: Cryosections of epididymides from WT or Aire ${ }^{-/-}$mice were probed with FITC-labeled antimouse IgG; positive signal represents endogenously bound autoantibodies. $n=5$ WT mice (A); $n=12$ Aire $^{-/-}$mice (A); $n=2$ WT mice (C); $n=4$ Aire $^{-/-}$ mice (C). Scale bars: $100 \mu \mathrm{m}(\mathbf{A}) ; 50 \mu \mathrm{m}$ (C). whereas only 5 of 11 Aire $^{-/-}$males produced a copulation plug (Figure 1A). Those that did, required up to 2 weeks to mate, and plugs were often liquefied. In addition, only 2 of the Aire ${ }^{-1-}$ males produced viable litters, in contrast to 8 of the 10 females that mated with WT males (Figure 1, B and C). Average litter sizes of Aire $^{-1-}$ and WT males, excluding nonproductive males, were $2.0 \pm 1.0$ and $5.9 \pm 1.5$ pups, respectively $(P=0.1)$ (Figure 1C).
Testicular Atrophy and Germ Cell Loss Occur in a Subset of Aire ${ }^{-/-}$Males

Overall, gross morphology and tissue weights were comparable between genotypes, with the exception of several males that had reduced testicular weight compared with WT controls or the remaining Aire ${ }^{-l-}$ males (Figure 2, A and C). When matched for age, testis weight did not differ significantly between genotypes. However, of 34 total males 
examined, 5 (approximately 15\%) had small testis, weighing half or less of the mean testes weight of the other mice within their respective age groups. This included one 12-week-old Aire ${ }^{-l-}$ male, two approximately 22-week-old Aire ${ }^{-l-}$ males, and two of four 35- to 55week-old Aire ${ }^{-l-}$ males.

Histologic evaluation of the testes revealed differences in the minor subset of males that were affected by testicular atrophy. In these mice, severe reductions in spermatogenic cells were apparent, particularly at the spermatid/spermatozoan stages (Figure 2, B and D). Loss in spermatogenesis appeared to be progressive; in one aging (150-day-old) animal, atrophic tubules and spermatogonia were present in some tubules, whereas other tubules contained Sertoli cells and spermatogonia together with sloughed germ cell tubule lumen and still other tubules had overtly normal histology with a few pyknotic spermatids (Figure 2, B and D). Consistent with this, germ cells displayed a rounded morphology, were displaced from the basal region of the tubule, and had reduced expression of the proliferation marker, Ki-67 (Figure 3). This trend held true even in testis from Aire ${ }^{-1-}$ mice without overt evidence of testicular inflammation or atrophy. Lymphatics were often dilated, and there was increased cellularity and lymphocyte infiltration in the interstitial space (Figure 2, B and D).

Immunohistochemistry and immunofluorescence analysis confirmed presence of $\mathrm{T}$ cells and macrophages in atrophic testis. $\mathrm{CD}^{+} \mathrm{T}$-cell infiltration was observed in 1 of 20 knockout mice examined (5\%), mostly contained within the interstitial space (Figure 4A). Occasional T cells could be identified within the lumen of seminiferous tubules that were devoid of germ cells. In addition, numerous macrophages were found in the interstitial space of an atrophic Aire knockout testis (Figure 4B). To determine whether testis- or sperm-reactive antibodies were produced by Aire ${ }^{-1-}$ mice, cryosections of testis from $\operatorname{Rag} 2^{-1-}$ mice (used to ensure absence of endogenous antibodies) were probed with sera from WT or Aire ${ }^{-l-}$ mice. Of the four mice examined, three had similar reactivity to WT control mice. Serum from one mouse, however, showed strong reactivity to spermatid heads (Figure 5A). The spectrum of possible antigenic targets of testicular cells was examined by probing lysate of $R a g 2^{-/-}$testis with serum from 7- to 9-week-old WT or Aire ${ }^{-1-}$ males by Western blot analysis. Although sera from 7- to 9-week-old wild-type mice had minimal reactivity to testicular lysate, serum reactivity was apparent in Aire ${ }^{-1-}$ mice of this age (Figure 5B). In 4to 5-week-old mice, serum antibody reactivity against testicular lysate was also present: sera from one of two WT mice, and all three Aire ${ }^{-1-}$ mice, examined showed reactivity to testicular lysate. Finally, endogenous binding of autoantibodies was investigated by direct immunofluorescence, probing testis of Aire ${ }^{-1-}$ (Figure 5C) or WT mice (data not shown; $n=3$ per genotype) with fluorescein isothiocyanate-conjugated anti-mouse IgG. Surprisingly, little or no endogenous antibody binding was observed.

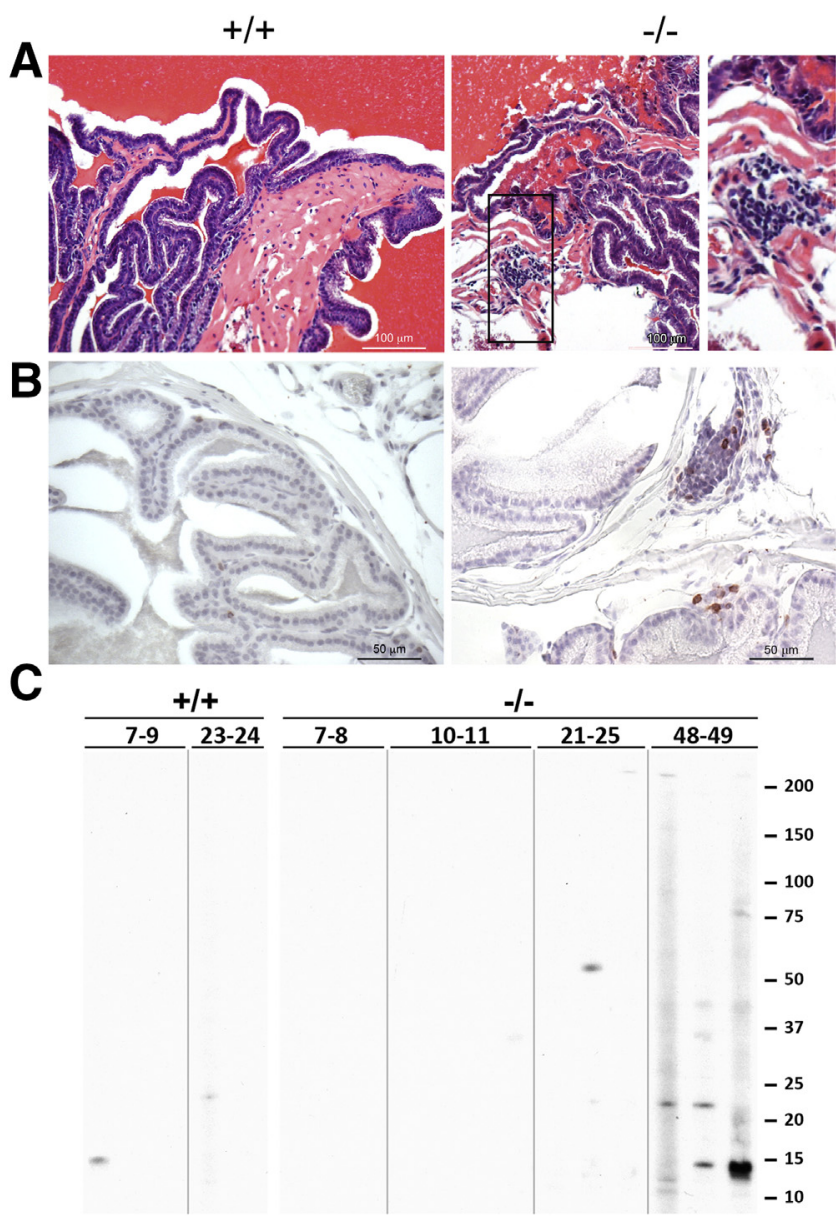

Figure 10 Autoimmunity against the seminal vesicle of Aire ${ }^{-/-}$mice. A and B: Representative sections of seminal vesicle from wild-type (WT) or Aire $^{-/-}$mice were stained with hematoxylin and eosin (A) or antibody against CD3 (B). Boxed area in $\mathbf{A}$ is shown at higher magnification to the right. C: Seminal vesicle lysate from a $\mathrm{Rag}^{-1-}$ mouse was probed with sera from WT and Aire ${ }^{-1-}$ mice. Each lane represents an individual mouse; ages in weeks are indicated at the top, and numbers on right represent the molecular weight marker $(\mathrm{kDa}) . n=7$ WT mice $(\mathbf{A}$ and $\mathbf{B}) ; n=19$ Aire $^{-/-}$ mice (A and B). Scale bars: $100 \mu \mathrm{m}(\mathbf{A}) ; 50 \mu \mathrm{m}$ (B).

\section{Infertility in Aire ${ }^{-/-}$Mice Is Associated with} Disruptions in Testosterone Production and Spermatogenesis and Testicular Autoimmunity

The histologic findings of the testis led us to ask whether steroidogenesis and/or spermatogenesis were impaired in mice lacking Aire. Neither concentrations of LH nor FSH in the serum were significantly different between WT and Aire $^{-1-}$ animals (LH: WT, $0.07 \pm 0.03 \mathrm{ng} / \mathrm{mL}, n=5$; Aire $\left.^{-l-}, 0.19 \pm 0.08 \mathrm{ng} / \mathrm{mL}, n=13 ; P=0.37\right)(\mathrm{FSH}: \mathrm{WT}$, $17.75 \pm 1.32 \mathrm{ng} / \mathrm{mL} ;$ Aire $^{-/-}, 22.05 \pm 2.56 \mathrm{ng} / \mathrm{mL}$; $P=0.33$ ). However, serum testosterone was reduced by $>50 \%$ in all males, including the two males that produced small litters (Figure 6A).

To examine sperm abundance and motility, epididymides were dissected and weighed, and spermatozoa from 


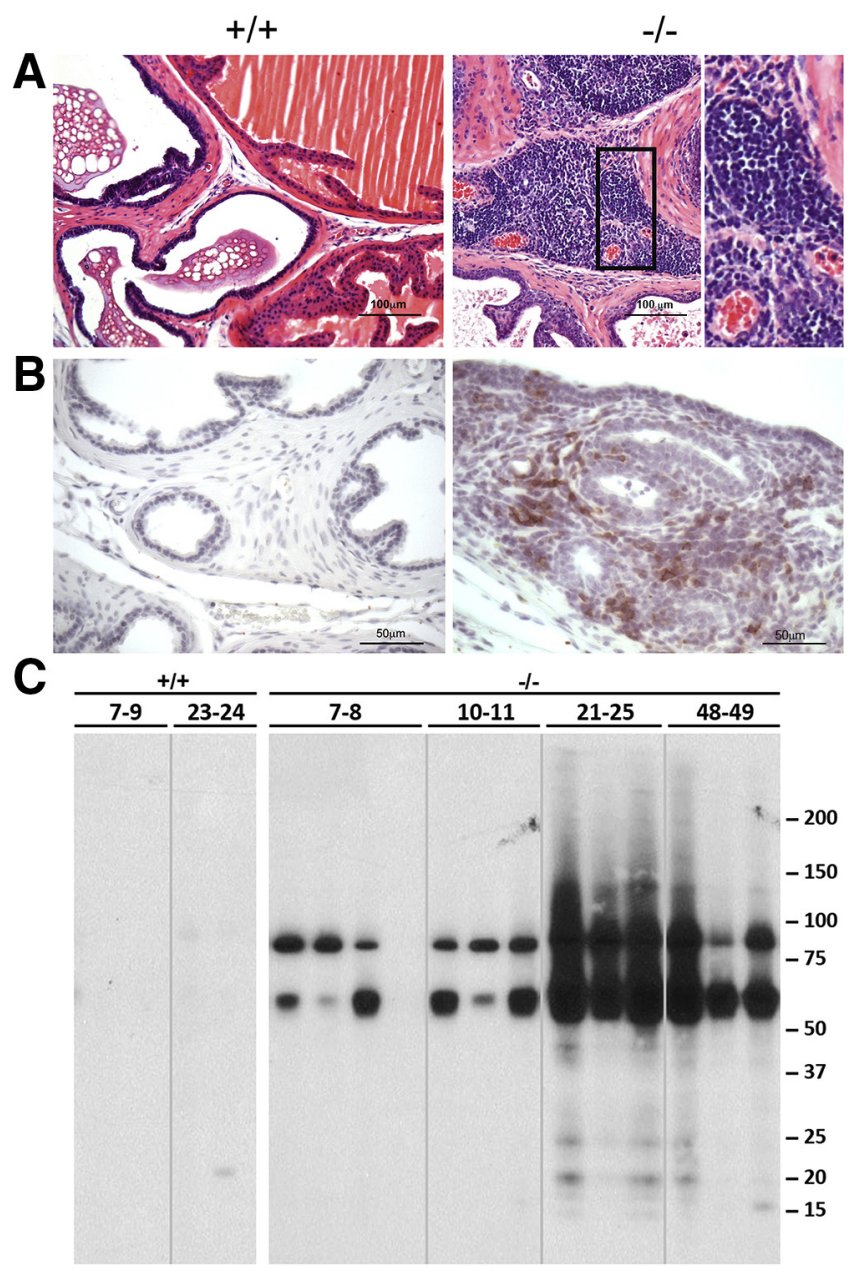

Figure 11 Autoimmunity against the prostate gland of Aire ${ }^{-/-}$mice. A and B: Representative sections of prostate from wild-type (WT) or Aire ${ }^{-/-}$ mice were stained with hematoxylin and eosin (A) or antibody against CD3 (B). Boxed area in A is shown at higher magnification to the right. C: Prostate lysate from a $\mathrm{Rag}^{-/-}$mouse was probed with sera from WT and Aire $^{-/-}$mice. Each lane represents an individual mouse; ages in weeks are indicated at the top, and numbers on right represent the molecular weight marker (kDa). $n=7$ WT mice (A and $\mathbf{B}) ; n=20$ Aire $^{-/-}$mice (A and $\left.\mathbf{B}\right)$. Scale bars: $100 \mu \mathrm{m}(\mathbf{A}) ; 50 \mu \mathrm{m}$ (B).

the caudal region were obtained by the swim-up method. Caudal epididymal weight of Aire $^{-/-}$mice was not significantly different from that of controls (WT: $8.18 \pm 0.27 \mathrm{mg}, n=8$; Air $^{-l-}: 9.66 \pm 0.60 \mathrm{mg}, n=9$; $P=0.11$ ), and sperm recovery was similar between WT and Aire ${ }^{-1-}$ mice (Figure 6B). In a separate group of mice, neither DSP nor sperm production efficiency differed significantly between WT and Aire ${ }^{-1-}$ males (Figure 6, C and D). Computer-assisted sperm analysis in two of four Aire ${ }^{-1-}$ males examined revealed total and progressive sperm motility was comparable to those of WT controls (data not shown). In the remaining two Aire ${ }^{-1-}$ males, however, epididymal sperm were undetectable. One of these males (number 851) (Figure 6, C and D) also showed dramatically reduced DSP and sperm production efficiency, whereas the other (number 835) exhibited DSP and sperm production efficiency comparable to the WT controls and other Aire ${ }^{-l-}$ males; both mice had normal testis weight. A third male (number 1297), which had reduced testis weight, had low DSP but normal sperm production efficiency.

In vitro fertilization was performed to directly examine sperm function in Aire $^{-/-}$. Fertilization with WT sperm produced two-cell and blastocyst stage embryos with a success rate of $54 \%$ and $40 \%$ of total oocytes, respectively (Figure 6E). However, sperm from Aire ${ }^{-1-}$ males had only a 9\% success rate in producing two-cell embryos, none of which progressed to the blastocyst stage.

\section{Identification of Potential Testis Target Autoantigens}

Bioinformatic analysis of an existing data set ${ }^{40}$ was used to identify Aire-regulated testis-specific genes that, if unexpressed in Aire ${ }^{-l-}$ thymus, might contribute to autoimmune disease targeting this organ. To this end, the over representation of Aire target genes was evaluated in different sets of tissue-specific genes across diverse tissues. First, 47 genome-wide RNA-sequencing data sets were integrated from two previous studies ${ }^{38,43}$ that cover comprehensive gene expression of multiple tissues, including testis. Sets of tissue-specific genes were identified for each tissue (Supplemental Figure S2) on the basis of differential gene expression patterns across these tissues (Supplemental Figure S1). On average, there were 680 tissue-specific genes per tissue. Interestingly, testis expressed the highest number of tissue-specific genes of any tissue (approximately 2500 testis-specific genes). Gene Ontology enrichment analysis revealed cellular functions associated with spermatogenesis, meiosis, cilium morphogenesis, axoneme assembly, inner dynein arm assembly, Piwi-interacting RNA biogenesis, and fertilization (Supplemental Figure S3).

Aire target genes were highly enriched in gene sets specifically expressed in the testis, thymus, and other tissues (Figure 7). For testis, $>200$ testis-specific genes targeted by Aire were identified for both up-regulation and downregulation $\left(P<10^{-9}\right)$ (Supplemental Table S1).

Widespread Autoimmunity in the Reproductive Tract of Aire $^{-/-}$Males

In contrast to the testes, lymphocytic infiltration occurred in epididymides of 15 of 22 Aire $^{-1-}$ males, as opposed to those of WT males examined (Figure 8, A and C). This held true even if epididymal gross morphology appeared normal, and if epididymal sperm were present. A complete absence of epididymal sperm was observed in six mice, all of which displayed abnormally interstitial morphology, characterized by increased intratubular space, fibrosis, and loss of epithelial integrity. The presence of $\mathrm{T}$ cells was confirmed by probing epididymal sections with anti-CD3 antibody. T cells were observed within caput, corpus, and cauda of the 


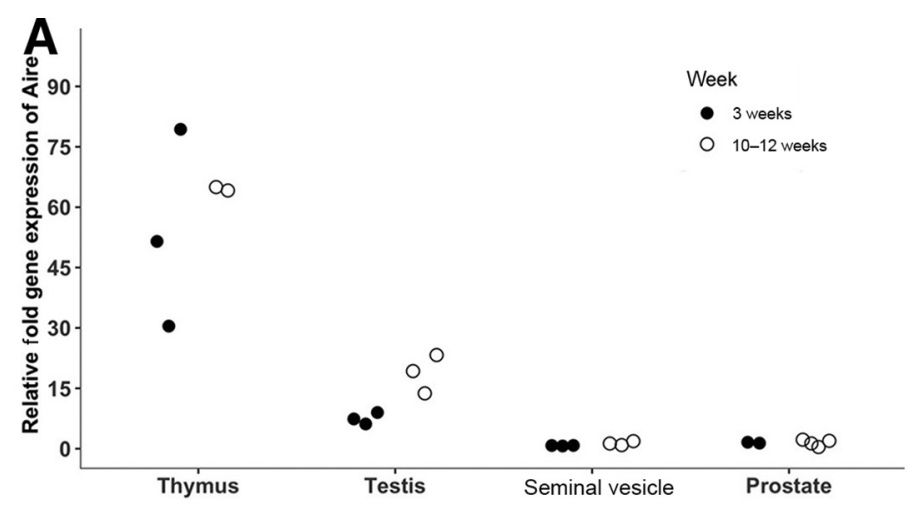

B
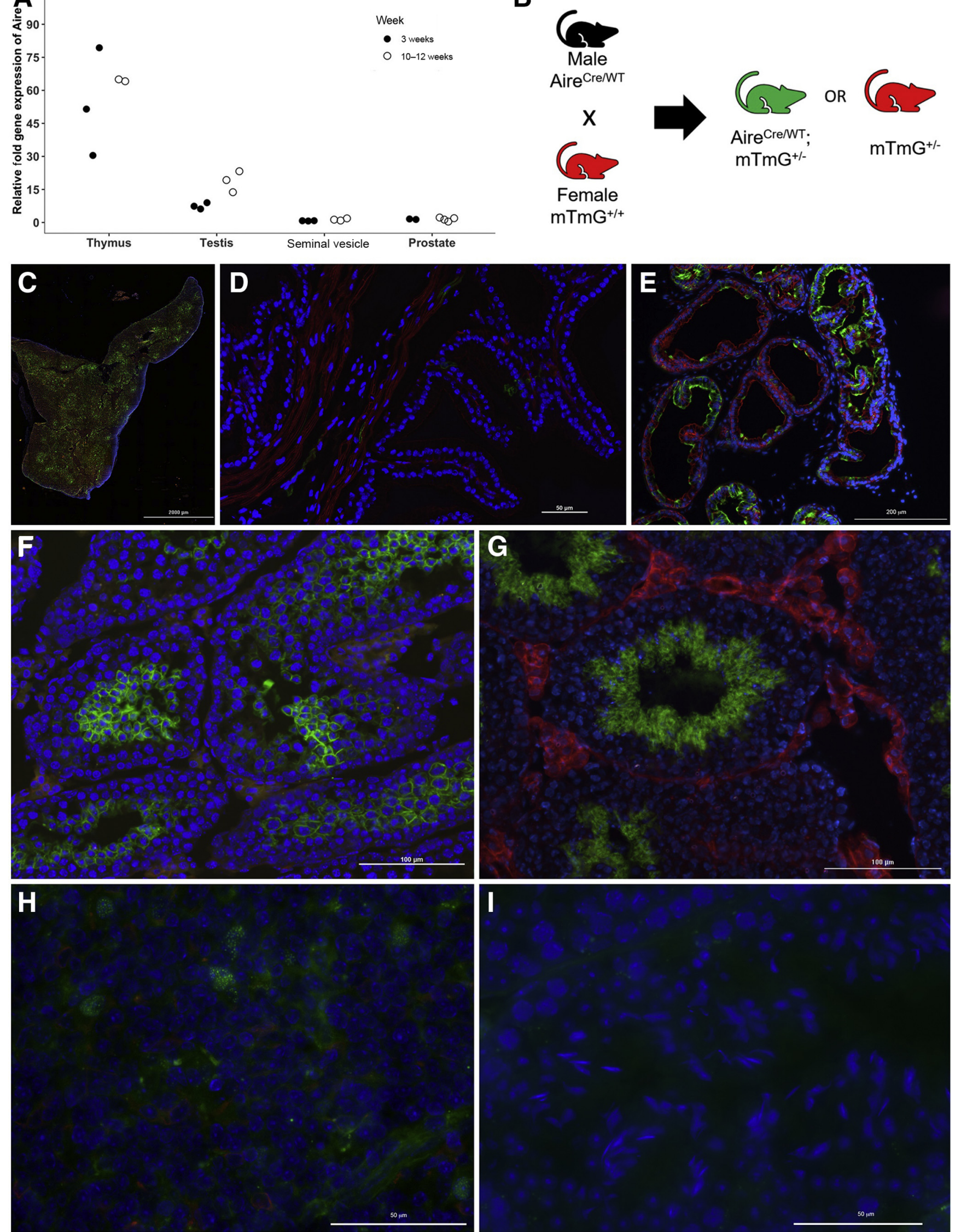
epididymis, sometimes in aggregates or within ductal epithelium (Figure 8, B and D). Binding of serum autoantibodies to caput (data not shown) and cauda epididymal sections of Rag $2^{-1-}$ mice consistently revealed reactivity to apical epithelium and connective tissue in all mice examined, as well as to caudal sperm in three of four mice (Figure 9A). Western blot analysis of isolated caudal epididymal protein revealed strong autoantigen reactivity of Aire $^{-l-}$ serum to multiple proteins as early as 8 weeks of age, and in all mice examined by 21 weeks (Figure 9B). Particularly prominent were autoantigens of 20, 25, 37, and approximately $45 \mathrm{kDa}$. Finally, direct immunofluorescence detected prominent antibody deposition within the epithelium, basement membrane, and connective tissue of epididymal tubules (Figure 9C). As in testis sections, sperm were not directly bound.

Seminal vesicles were also examined in WT and Aire ${ }^{-/-}$ mice, and although gross morphology of these glands was unaltered, a mild lymphocytic infiltrate, including $\mathrm{CD}^{+} \mathrm{T}$ cells, within the loose connective tissue below the mucosal epithelium was observed in 16 of 19 Aire $^{-1-}$ mice (84\%) (Figure 10, A and B). Autoantibodies against the seminal vesicles were generated, although these occurred in a minority of mice only after 6 months of age (Figure 10C). Finally, the presence of pronounced prostatitis was confirmed in 17 of 19 (89\%) of Aire ${ }^{-l-}$ mice and antiprostate autoantibody formation (Figure 11), as reported previously. ${ }^{29,44}$

\section{Aire mRNA Is Expressed in the Testis}

To determine whether Aire is expressed in male reproductive tissues, we analyzed transcript and protein expression using RT-qPCR, immunofluorescence, and an Aire-Cre-mTmG reporter system (Figure 12). RT-qPCR analysis for Aire mRNA expression showed low but detectable expression in the testis at 3 and 10 to 12 weeks of age, whereas expression was not detected in the seminal vesicles or the prostate gland (Figure 12A). Our $m T m G$ reporter recapitulated the expected pattern of Aire in mTECs of the thymus (Figure 12, B and C), and although no expression was observed in the seminal vesicle, reporter expression was observed in the prostate gland (Figure 12, D and E). The reporter system also showed that the Aire gene was expressed in the testis, specifically in the seminiferous epithelium, at 3 weeks of age, and spermatids were present in 9-week-old males (Figure 12, F and G). Aire protein expression in the testis was studied using immunofluorescence. Although Aire expression was readily detected in the thymus (Figure 12H), it was not seen in the testis, either at 3 or 12 weeks of age (data not shown) (Figure 12I). Aire protein expression was not detected in the prostate gland of mice at these ages.

\section{Discussion}

Mutations of the AIRE genes in both humans and mice impede the establishment of central immune tolerance and produce multiorgan autoimmune disease, characterized by the presence of autoreactive $\mathrm{T}$ cells and antibodies. ${ }^{15,17,45}$ Although differences exist between the organs of APS-1 patients and Aire ${ }^{-1-}$ mice, a shared pathology is premature gonadal insufficiency. ${ }^{17,25-27,45}$ One cause of early reproductive senescence in female mice on the $\mathrm{BALB} / \mathrm{c}$ genetic background is an age-dependent, autoimmune-associated loss of ovarian follicular reserves and failed embryonic development. ${ }^{33,46}$ However, information on fertility and reproductive immune targets in male Aire-deficient mice has been scattered and incomplete. This study showed that most male Aire ${ }^{-l-}$ mice on the Balb/cJ genetic background were infertile; the few mice that did produce offspring had small litter sizes. Aire ${ }^{-1-}$ mice also produced low levels of testosterone and developed autoimmune disease against many components of the male reproductive tract. Furthermore, sperm produced by Aire Al- $^{-/}$mice had severely diminished fertilizing potential, and a subset of males had oligospermia with an apparent disruption of the blood-testis barrier.

In men with APS-1, gonadal insufficiency occurs in approximately $12 \%$ to $14 \%$ of cases,${ }^{14}$ with most being diagnosed with primary hypogonadism and associated low testosterone levels; hypogonadotropism is not usually found in these patients. Male Aire ${ }^{-1-}$ mice share these changes. Interestingly, more than half of Aire ${ }^{-1-}$ mice also failed to mate over a 3-week period. Testosterone levels were roughly one-third of those of WT mice. Produced by Leydig cells, testosterone controls sexual behavior in mice and in vertebrates ${ }^{47}$; thus, reduced testosterone in Aire ${ }^{-1-}$ mice may contribute to their lack of copulation, as evidenced by infrequent detection of copulatory plugs.

Although most animals examined in this study exhibited normal gross and histologic testicular morphology, a subset of mice had severe autoimmune orchitis with reduced testis size, depletion of germ cells, and reduction of DSP. This was associated with serum autoantibody formation and infiltration of $\mathrm{T}$ cells and macrophages, which may contribute to the destruction of testosterone-producing Leydig cells. More importantly, mature spermatozoa

Figure 12 Expression analysis of Aire in the male reproductive tract. A: Quantitative RT-PCR analysis of Aire in indicated organs of 3-week-old and 10- to 12-week-old males. B: Schematic representation of generation of Aire-Cre reporter mice. Aire ${ }^{\text {Cre/WT }}$ males were bred with female $\mathrm{mTmG}$ mice, resulting in $50 \%$ of the offspring Aire ${ }^{\text {Cre/WT}} ; m T m G$. Males of this genotype were sacrificed at 3 or 9 weeks of age, and thymus (C) and reproductive tract tissues [seminal vesicle (D), prostate gland (E), testis (F, 3-week-old male; G, 9-week-old male)] were dissected and analyzed by epifluorescence microscopy. $\mathbf{H}$ and $\mathbf{I}$ : Immunofluorescence imaging of Aire in thymus (H) and testis (I) of a 3-week-old male. Scale bars: $2000 \mu \mathrm{m}(\mathbf{C}) ; 50 \mu \mathrm{m}(\mathbf{D}, \mathbf{H}$, and I); $200 \mu \mathrm{m}(\mathbf{E}) ; 100 \mu \mathrm{m}(\mathbf{F}$ and $\mathbf{G})$. 
contain numerous specific proteins ${ }^{8}$ that are potentially immunogenic in both men and women. Anti-sperm antibodies can form following trauma, inflammation, or vasectomy, ${ }^{48}$ and are present in significantly higher proportion in infertile men than in fertile men. ${ }^{49,50}$ These antibodies are clinically important when $>50 \%$ of the spermatozoa are coated with antibodies that can block sperm penetration and decrease in vitro fertilization rates. ${ }^{51,52}$ Hubert et $\mathrm{al}^{26}$ speculated that anti-sperm autoantibodies are causative for decreased fertility in Aire-deficient males on the B6 background. Intriguingly, our bioinformatics analysis revealed a plethora of testis-specific genes regulated by Aire in the thymus, and thus identified potential autoimmune targets. Although the blood-testes barrier plays an important role in sequestering germ cell from insult by the immune system, ${ }^{53}$ no endogenous antibodies were seen in seminiferous tubules of Aire ${ }^{-l-}$ mice, suggesting that anti-sperm antibodies in these mice do not reach sperm in the testis in vivo. The blood-testes barrier may have remained intact, at least before fulminant inflammation. It seems likely that Aire may function through its role in regulating deletion of selfreactive $\mathrm{T}$ cells, in turn regulating antibody production and/ or shaping of regulatory T cells. Future studies will dissect the causative relationships between anti-sperm $\mathrm{T}$ cells, antibodies, and infertility.

The study showed significantly lower in vitro fertilization success rates, with only $9 \%$ of wild-type oocytes developing to the two-cell stage, and none reaching the blastocyst stage, after being incubated with epididymal sperm from BALB/c Aire-deficient mice. It is possible that the observed orchidoepididymitis impacts the health and quality of the developing sperm, causing reduced fertilization potential. Although both reduced testosterone and local/systemic testicular inflammation can contribute to germ cell loss and infertility, ${ }^{54}$ only approximately $15 \%$ of the Aire ${ }^{-/-}$male mice had evidence of acute testicular inflammation. On the other hand, $68 \%$ of the animals had ongoing inflammation and/or fibrosis that suggested a previous inflammatory event. There was considerable autoantibody binding to basal epithelium of epididymal tubules. Epididymitis is the most common male reproductive tract inflammatory disease, impacting $>600,000$ males annually, and can lead to secondary involvement of the testis. ${ }^{55,56}$ Secretory products of epididymal epithelium contribute to completion of sperm development, enhancement of motility, and the ability to bind the zona pellucida. ${ }^{57,58} \mathrm{We}$ hypothesize that the epididymis is the initial target of the male reproductive tract in Aire-deficient mice, and that abundant antibody deposition within the epididymis alters the ability of tubular epithelium to transport and secrete the requisite seminal plasma proteins for complete spermatozoa development, thereby impairing their fertilization potential.

Chronic prostatitis and chronic pelvic pain syndrome in men is a common but poorly understood condition. $\mathrm{Pa}$ tients present urologic symptoms, nonspecific discomfort in the pelvic region, and sexual dysfunction. ${ }^{59}$ Despite initial speculation that these disorders had a bacterial etiology, it is now believed that most chronic prostatitis and chronic pelvic pain syndrome cases have noninfectious origins. ${ }^{56,60}$ The presence of prostatic immune aggregates in chronic prostatitis and chronic pelvic pain syndrome is common, ${ }^{61,62}$ and some patients can generate a recall $\mathrm{T}$-cell response when challenged with seminal plasma ${ }^{63}$ both of which suggest a potential autoimmune component to chronic prostatitis and chronic pelvic pain syndrome. Aire-deficient mice on a mixed $(129 / \mathrm{Sv} \times$ C57BL/6) $\mathrm{F}_{2}$ genetic background develop spontaneous immunity to the prostate autoantigen seminal vesicle secretory protein $2,{ }^{29}$ resulting in moderate to severe prostatitis in $>70 \%$ of the mice. In the current study, this result was confirmed by nearly $90 \%$ of the animals on a congenic BALB/c background developing severe prostate lymphocytic infiltration and autoantibody generation. Background genetics has a significant influence on the severity of disease and the range of autoantigens targeted in mouse models of Aire deficiency. ${ }^{28}$ However, some target organs, such as the prostate, are consistent across strains. Interestingly, the dominant prostate antigens in Aire ${ }^{-1-}$ BALB/c mice are not seminal vesicle secretory protein 2, but instead a higher-molecular-weight protein, identification of which is currently underway. Nevertheless, a deficiency in Aire is a good model for the study of chronic autoimmune prostatitis.

These studies of expression of Aire in the male reproductive tract raise the possibility that Aire in developing sperm contributes to fertility. RT-qPCR and reporter gene analyses confirm that the Aire gene is expressed in the seminiferous epithelium during the first wave of spermatogenesis. Reporter expression was observed in developing sperm, possibly pachytene spermatocytes, and early round spermatids. ${ }^{64}$ Interestingly, reporter expression progressed to elongated spermatids in the 9-week-old mouse but did not reappear in earlier stages of spermatogenesis at this age, suggesting that Aire expression is transient. This result is in general agreement with that of Schaller et al, ${ }^{65}$ who reported Aire expression in spermatogonia of 3week-old, but not older, mice. Unlike that study, however, this study did not have expression in the spermatogonia, which lie along the basement membrane, suggesting that Aire is transcribed after this stage. Because the initial wave of spermatogenesis is essential for proper development of fertility in mice, the expression of Aire in these cells may contribute directly to male fertility, independently of the immune system.

Aire reporter gene expression was also observed in the prostate gland. Aire is regulated by androgen receptor, which is expressed by the developing prostate gland. ${ }^{66,67} \mathrm{In}$ contrast, mRNA in this tissue was undetectable. Collectively, these results raise the possibility that transient expression of Aire occurs in the prostate during embryogenesis and/or early postnatal life through regulation by the androgen receptor. 
In summary, we have found that targeted deletion of Aire in male mice results in fertility problems similar to those afflicting men with APS-1. Infertility in these animals appears to be multifactorial. Lack of mating behavior, possibly due to low testosterone, may contribute to infertility, as could defects in spermatogenesis. However, these symptoms affect only $50 \%$ and $20 \%$ of animals, respectively. On the other hand, sperms themselves may be incapable of fertilization, as only a minor proportion of donors were able to produce two-cell embryos. These problems may be indicative of epididymal defects, as most animals had inflammatory infiltration into the epididymis, as well as antiepididymal autoantibodies. The correlation between impaired central immune tolerance and fertility has potential implications for not only male APS-1 patients but may also provide important insights into both male autoimmune and unexplained cases of infertility.

\section{Author Contributions}

B.D.W., B.K.P., P.S.K., M.K.N., G.B., S.H.A., and M.G.P. designed experiments and interpreted data; B.D.W., M.K.N., G.S., S.H.A., and K.S.B. performed experiments; H.W. and J.W. designed and performed bioinformatic analyses; B.D.W., S.H.A., and M.G.P. wrote the manuscript; all authors edited the manuscript.

\section{Supplemental Data}

Supplemental material for this article can be found at http://doi.org/10.1016/j.ajpath.2021.05.021.

\section{References}

1. Rutstein SO, Shah IH: Infecundity, Infertility, and Childlessness in Developing Countries. Calverton, MD, ORC Macro and the World Health Organization, 2004

2. Boivin J, Bunting L, Collins JA, Nygren KG: International estimates of infertility prevalence and treatment-seeking: potential need and demand for infertility medical care. Hum Reprod 2007, 22: $1506-1512$

3. Jarow JP, Sharlip ID, Belker AM, Lipshultz LI, Sigman M, Thomas AJ, Schlegel PN, Howards SS, Nehra A, Damewood MD, Overstreet JW, Sadovsky R: Best practice policies for male infertility. J Urol 2002, 167:2138-2144

4. Sullivan R: Male fertility markers, myth or reality. Anim Reprod Sci 2004, 82-83:341-347

5. Esteves SC, Hamada A, Kondray V, Pitchika A, Agarwal A: What every gynecologist should know about male infertility: an update. Arch Gynecol Obstet 2012, 286:217-229

6. Marrack P, Kappler J, Kotzin BL: Autoimmune disease: why and where it occurs. Nat Med 2001, 7:899-905

7. Jungwirth A, Giwercman A, Tournaye H, Diemer T, Kopa Z, Dohle G, Krausz C: European Association of Urology guidelines on male infertility: the 2012 update. Eur Urol 2012, 62:324-332

8. Suri A: Sperm specific proteins-potential candidate molecules for fertility control. Reprod Biol Endocrinol 2004, 2:10

9. Baker HW: Reproductive effects of nontesticular illness. Endocrinol Metab Clin North Am 1998, 27:831-850
10. DeVoss JJ, Anderson MS: Lessons on immune tolerance from the monogenic disease APS1. Curr Opin Genet Dev 2007, 17:193-200

11. Akirav EM, Ruddle NH, Herold KC: The role of AIRE in human autoimmune disease. Nat Rev Endocrinol 2011, 7:25-33

12. Kyewski B, Derbinski J: Self-representation in the thymus: an extended view. Nat Rev Immunol 2004, 4:688-698

13. Bjorses P, Aaltonen J, Vikman A, Perheentupa J, Ben-Zion G, Chiumello G, Dahl N, Heideman P, Hoorweg-Nijman JJ, Mathivon L, Mullis PE, Pohl M, Ritzen M, Romeo G, Shapiro MS, Smith CS, Solyom J, Zlotogora J, Peltonen L: Genetic homogeneity of autoimmune polyglandular disease type I. Am J Hum Genet 1996, 59:879-886

14. Ahonen P, Myllarniemi S, Sipila I, Perheentupa J: Clinical variation of autoimmune polyendocrinopathy-candidiasis-ectodermal dystrophy (APECED) in a series of 68 patients. N Engl J Med 1990, 322: 1829-1836

15. Soderbergh A, Myhre AG, Ekwall O, Gebre-Medhin G, Hedstrand H, Landgren E, Miettinen A, Eskelin P, Halonen M, Tuomi T, Gustafsson J, Husebye ES, Perheentupa J, Gylling M, Manns MP, Rorsman F, Kampe O, Nilsson T: Prevalence and clinical associations of 10 defined autoantibodies in autoimmune polyendocrine syndrome type I. J Clin Endocrinol Metab 2004, 89:557-562

16. Nagamine K, Peterson P, Scott HS, Kudoh J, Minoshima S, Heino M, Krohn KJ, Lalioti MD, Mullis PE, Antonarakis SE, Kawasaki K, Asakawa S, Ito F, Shimizu N: Positional cloning of the APECED gene. Nat Genet 1997, 17:393-398

17. Anderson MS, Venanzi ES, Klein L, Chen Z, Berzins SP, Turley SJ, Von Boehmer H, Bronson R, Dierich A, Benoist C, Mathis D: Projection of an immunological self shadow within the thymus by the Aire protein. Science 2002, 298:1395-1401

18. Derbinski J, Gabler J, Brors B, Tierling S, Jonnakuty S, Hergenhahn M, Peltonen L, Walter J, Kyewski B: Promiscuous gene expression in thymic epithelial cells is regulated at multiple levels. J Immunol 2005, 202:33-45

19. Org T, Chignola F, Hetenyi C, Gaetani M, Rebane A, Liiv I, Maran U, Mollica L, Bottomley MJ, Musco G, Peterson P: The autoimmune regulator PHD finger binds to non-methylated histone H3K4 to activate gene expression. EMBO Rep 2008, 9: 370-376

20. Koh AS, Kuo AJ, Park SY, Cheung P, Abramson J, Bua D, Carney D, Shoelson SE, Gozani O, Kingston RE, Benoist C, Mathis D: Aire employs a histone-binding module to mediate immunological tolerance, linking chromatin regulation with organspecific autoimmunity. Proc Natl Acad Sci U S A 2008, 105: $15878-15883$

21. Anderson MS, Venanzi ES, Chen Z, Berzins SP, Benoist C, Mathis D: The cellular mechanism of Aire control of T cell tolerance. Immunity 2005, 23:227-239

22. Liston A, Lesage S, Wilson J, Peltonen L, Goodnow CC: Aire regulates negative selection of organ-specific T cells. Nat Immunol 2003 , 4:350-354

23. Aschenbrenner K, D'Cruz LM, Vollmann EH, Hinterberger M, Emmerich J, Swee LK, Rolink A, Klein L: Selection of Foxp3+ regulatory $\mathrm{T}$ cells specific for self antigen expressed and presented by Aire + medullary thymic epithelial cells. Nat Immunol 2007, 8: 351-358

24. Malchow S, Leventhal DS, Lee V, Nishi S, Socci ND, Savage PA: Aire enforces immune tolerance by directing autoreactive $\mathrm{T}$ cells into the regulatory T cell lineage. Immunity 2016, 44:1102-1113

25. Kuroda N, Mitani T, Takeda N, Ishimaru N, Arakaki R, Hayashi Y, Bando Y, Izumi K, Takahashi T, Nomura T, Sakaguchi S, Ueno T, Takahama Y, Uchida D, Sun S, Kajiura F, Mouri Y, Han H, Matsushima A, Yamada G, Matsumoto M: Development of autoimmunity against transcriptionally unrepressed target antigen in the thymus of Aire-deficient mice. J Immunol 2005, 174:1862-1870

26. Hubert F-X, Kinkel SA, Crewther PE, Cannon PZF, Webster KE, Link M, Uibo R, O’Bryan MK, Meager A, Forehan SP, Smyth GK, 
Mittaz L, Antonarakis SE, Peterson P, Heath WR, Scott HS: Airedeficient C57BL/6 mice mimicking the common human 13-base pair deletion mutation present with only a mild autoimmune phenotype. J Immunol 2009, 182:3902-3918

27. Ramsey C, Winqvist O, Puhakka L, Halonen M, Moro A, Kämpe O, Eskelin P, Pelto-Huikko M, Peltonen L: Aire deficient mice develop multiple features of APECED phenotype and show altered immune response. Hum Mol Genet 2002, 11:397-409

28. Jiang W, Anderson MS, Bronson R, Mathis D, Benoist C: Modifier loci condition autoimmunity provoked by aire deficiency. J Exp Med 2005, 202:805-815

29. Hou Y, DeVoss J, Dao V, Kwek S, Simko JP, McNeel DG, Anderson MS, Fong L: An aberrant prostate antigen-specific immune response causes prostatitis in mice and is associated with chronic prostatitis in humans. J Clin Invest 2009, 119: 2031-2041

30. Committee for the Update of the Guide for the Care and Use of Laboratory AnimalsNational Research Council: Guide for the Care and Use of Laboratory Animals: Eighth Edition. Washington, DC, National Academies Press, 2011

31. Muzumdar MD, Tasic B, Miyamichi K, Li N, Luo L: A global double-fluorescent cre reporter mouse. Genesis 2007, 45: 593-605

32. Fan Y, Rudert WA, Grupillo M, He J, Sisino G, Trucco M: Thymusspecific deletion of insulin induces autoimmune diabetes. EMBO J 2009, 28:2812-2824

33. Warren BD, Ahn SH, McGinnis LK, Grzesiak G, Su R-W, Fazleabas AT, Christenson LK, Petroff BK, Petroff MG: Autoimmune regulator is required in female mice for optimal embryonic development and implantation. Biol Reprod 2019, 100: 1492-1504

34. Nguyen SL, Ahn SH, Greenberg JW, Collaer BW, Agnew DW, Arora R, Petroff MG: Integrins mediate placental extracellular vesicle trafficking to lung and liver in vivo. Sci Rep 2021, 11:1-16

35. Jimenez T, Sánchez G, Wertheimer E, Blanco G: Activity of the $\mathrm{Na}, \mathrm{K}$-Atpase A4 isoform is important for membrane potential, intracellular $\mathrm{Ca} 2+$, and $\mathrm{Ph}$ to maintain motility in rat spermatozoa. Reproduction 2010, 139:835-845

36. Nanjappa MK, Hess RA, Medrano TI, Locker SH, Levin ER, Cooke PS: Membrane-localized estrogen receptor 1 is required for normal male reproductive development and function in mice. Endocrinology 2016, 157:2909-2919

37. Oakberg EF: Duration of spermatogenesis in the mouse and timing of stages of the cycle of the seminiferous epithelium. Am J Anat 1956, 99:507-516

38. Li B, Qing T, Zhu J, Wen Z, Yu Y, Fukumura R, Zheng Y, Gondo Y, Shi L: A comprehensive mouse transcriptomic bodymap across 17 tissues by RNA-seq. Sci Rep 2017, 7:4200

39. Pervouchine DD, Djebali S, Breschi A, Davis CA, Barja PP, Dobin A, Tanzer A, Lagarde J, Zaleski C, See L-H, Fastuca M, Drenkow J, Wang H, Bussotti G, Pei B, Balasubramanian S, Monlong J, Harmanci A, Gerstein M, Beer MA, Notredame C, Guigó R, Gingeras TR: Enhanced transcriptome maps from multiple mouse tissues reveal evolutionary constraint in gene expression. Nat Commun 2015, 6:5903

40. Sansom SN, Shikama-Dorn N, Zhanybekova S, Nusspaumer G, Macaulay IC, Deadman ME, Heger A, Ponting CP, Holländer GA: Population and single-cell genomics reveal the Aire dependency, relief from polycomb silencing, and distribution of self-antigen expression in thymic epithelia. Genome Res 2014, 24:1918-1931

41. Ashburner M, Ball CA, Blake JA, Botstein D, Butler H, Cherry JM, Davis AP, Dolinski K, Dwight SS, Eppig JT, Harris MA, Hill DP, Issel-Tarver L, Kasarskis A, Lewis S, Matese JC, Richardson JE, Ringwald M, Rubin GM, Sherlock G: Gene ontology: tool for the unification of biology. Nat Genet $2000,25: 25$
42. Huang DW, Sherman BT, Lempicki RA: Bioinformatics enrichment tools: paths toward the comprehensive functional analysis of large gene lists. Nucleic Acids Res 2009, 37:1-13

43. Yue F, Cheng Y, Breschi A, Vierstra J, Wu W, Ryba T, et al: A comparative encyclopedia of DNA elements in the mouse genome. Nature 2014, 515:355

44. Gavanescu I, Benoist C, Mathis D: B cells are required for airedeficient mice to develop multi-organ autoinflammation: a therapeutic approach for APECED patients. Proc Natl Acad Sci U S A 2008, 105:13009-13014

45. Perheentupa J: Autoimmune polyendocrinopathy-candidiasisectodermal dystrophy. J Clin Endocrinol Metab 2006, 91: $2843-2850$

46. Jasti S, Warren BD, McGinnis LK, Kinsey WH, Petroff BK, Petroff MG: The autoimmune regulator prevents premature reproductive senescence in female mice. Biol Reprod 2012, 86:1-9

47. Hull EM, Dominguez JM: Sexual behavior in male rodents. Horm Behav 2007, 52:45-55

48. Meinertz H, Linnet L, Fogh-Andersen P, Hjort T: Antisperm antibodies and fertility after vasovasostomy: a follow-up study of 216 men. Fertil Steril 1990, 54:315-321

49. Haas GG Jr, Cines DB, Schreiber AD: Immunologic infertility: identification of patients with antisperm antibody. N Engl J Med 1980, 303:722-727

50. Heidenreich A, Bonfig R, Wilbert DM, Strohmaier WL, Engelmann UH: Risk factors for antisperm antibodies in infertile men. Am J Reprod Immunol 1994, 31:69-76

51. Eggert-Kruse W, Leinhos G, Gerhard I, Tilgen W, Runnebaum B: Prognostic value of in vitro sperm penetration into hormonally standardized human cervical mucus. Fertil Steril 1989, 51:317-323

52. Clarke GN, Lopata A, McBain JC, Baker HW, Johnston WI: Effect of sperm antibodies in males on human in vitro fertilization (IVF). Am J Reprod Immunol Microbiol 1985, 8:62-66

53. Wheeler K, Tardif S, Rival C, Luu B, Bui E, del Rio R, Teuscher C, Sparwasser T, Hardy D, Tung KSK: Regulatory T cells control tolerogenic versus autoimmune response to sperm in vasectomy. Proc Natl Acad Sci U S A 2011, 108:7511

54. Kalyani RR, Gavini S, Dobs AS: Male hypogonadism in systemic disease. Endocrinol Metab Clin North Am 2007, 36:333-348

55. Luzzi GA, O’Brien TS: Acute epididymitis. BJU Int 2001, 87 : 747-755

56. Krieger JN: Epididymitis, orchitis, and related conditions. Sex Transm Dis 1984, 11:173-181

57. Moore HD, Curry MR, Penfold LM, Pryor JP: The culture of human epididymal epithelium and in vitro maturation of epididymal spermatozoa. Fertil Steril 1992, 58:776-783

58. Kirchhoff C, Osterhoff C, Pera I, Schroter S: Function of human epididymal proteins in sperm maturation. Andrologia 1998, 30: $225-232$

59. Alexander RB, Trissel D: Chronic prostatitis: results of an internet survey. Urology 1996, 48:568-574

60. de la Rosette JJ, Hubregtse MR, Meuleman EJ, Stolk-Engelaar MV, Debruyne FM: Diagnosis and treatment of 409 patients with prostatitis syndromes. Urology 1993, 41:301-307

61. Kohnen PW, Drach GW: Patterns of inflammation in prostatic hyperplasia: a histologic and bacteriologic study. J Urol 1979, 121: $755-760$

62. Theyer G, Kramer G, Assmann I, Sherwood E, Preinfalk W, Marberger M, Zechner O, Steiner GE: Phenotypic characterization of infiltrating leukocytes in benign prostatic hyperplasia. Lab Invest 1992, 66:96-107

63. Alexander RB, Brady F, Ponniah S: Autoimmune prostatitis: evidence of T cell reactivity with normal prostatic proteins. Urology 1997, 50:893-899

64. Bellve AR, Cavicchia JC, Millette CF, O'Brien DA, Bhatnagar YM, Dym M: Spermatogenic cells of the prepubertal mouse. J Cell Biol 1977, 74:68-85 
65. Schaller CE, Wang CL, Beck-Engeser G, Goss L, Scott HS, Anderson MS, Wabl M: Expression of aire and the early wave of apoptosis in spermatogenesis. J Immunol 2008, 180: $1338-1343$

66. Zhu ML, Bakhru P, Conley B, Nelson JS, Free M, Martin A, Starmer J, Wilson EM, Su MA: Sex bias in CNS autoimmune disease mediated by androgen control of autoimmune regulator. Nat Commun 2016, 13:11350

67. Shibata M, Epsi NJ, Xuan S, Nitrofanova A, Shen: MM: Bipotent progenitors do not require androgen receptor for luminal specification during prostate organogenesis. Stem Cell Rep 2020, 15: $1026-1036$ 